\title{
Roles of leaf trichomes in heat transfers and gas-exchange characteristics across environmental gradients
}

\author{
Gaku Amada $^{1}$, Yoshiko Kosugi ${ }^{1}$, Kanehiro Kitayama $^{1}$, and Yusuke Onoda ${ }^{1}$ \\ ${ }^{1}$ Kyoto University
}

December 14, 2020

\begin{abstract}
Dense leaf trichomes can directly decrease gas fluxes through increased gas diffusion resistance and indirectly increase gas fluxes through increased leaf temperature due to increased heat diffusion resistance, which may contribute to adaptation to dry and/or low-temperature conditions. However, it remains unclear whether the leaf-trichome resistance increases or decreases the gas-exchange rates through combined direct and indirect effects. We focused on Metrosideros polymorpha, a dominant tree species inhabiting a large range of environmental gradients in the Hawaiian Islands, whose leaves have an enormous variation in trichome thickness on the lower surface. In five elevational sites, we measured leaf morphological and physiological traits including trichome thickness, gas-exchange characteristics, and leaf temperature. The trichome thickness was largest in the coldest and driest site and thinnest at the wettest site. Leaf temperature was significantly increased with trichome thickness. With biophysical and physiological models, we show that leaf trichomes can increase the daily photosynthesis through increasing leaf temperature only in the cold alpine area. The daily water-use efficiency can be lower with increasing leaf trichomes at any elevational sites. Therefore, in terms of diffusion resistance, the leaf trichomes of $M$. polymorpha can contribute to the adaptation to low-temperature environments but not to dry environments.
\end{abstract}

\section{Roles of leaf trichomes in heat transfers and gas-exchange characteristics across environmental gradients}

Gaku Amada ${ }^{1}$, Kosugi Yoshiko ${ }^{1}$, Kanehiro Kitayama $^{1}$, Yusuke Onoda ${ }^{1}$

${ }^{1}$ Graduate School of Agriculture, Kyoto University, Kitashirakawa Oiwake- cho, Sakyo-ku, Kyoto, 606- 8502, Japan

*Corresponding author: Gaku Amada

Email: amada.gaku@gmail.com, TEL: +81-75-753-6080, FAX: +81-75-753-6080

Funding: Japan Society for the Promotion of Science; The Kyoto University Foundation; Internship Subsidy from CoHHO (the Connectivity of Hills, Humans, and Oceans) Educational Program.

\section{Abstract}

Dense leaf trichomes can directly decrease gas fluxes through increased gas diffusion resistance and indirectly increase gas fluxes through increased leaf temperature due to increased heat diffusion resistance, which may contribute to adaptation to dry and/or low-temperature conditions. However, it remains unclear whether the leaf-trichome resistance increases or decreases the gas-exchange rates through combined direct and indirect effects. We focused on Metrosideros polymorpha, a dominant tree species inhabiting a large range of 
environmental gradients in the Hawaiian Islands, whose leaves have an enormous variation in trichome thickness on the lower surface. In five elevational sites, we measured leaf morphological and physiological traits including trichome thickness, gas-exchange characteristics, and leaf temperature. The trichome thickness was largest in the coldest and driest site and thinnest at the wettest site. Leaf temperature was significantly increased with trichome thickness. With biophysical and physiological models, we show that leaf trichomes can increase the daily photosynthesis through increasing leaf temperature only in the cold alpine area. The daily water-use efficiency can be lower with increasing leaf trichomes at any elevational sites. Therefore, in terms of diffusion resistance, the leaf trichomes of $M$. polymorpha can contribute to the adaptation to low-temperature environments but not to dry environments.

\section{Key words}

leaf hair, diffusion resistance, photosynthesis, water-use efficiency, leaf temperature, drought, low temperature, diurnal variation, altitude,

Metrosideros polymorpha

\section{Acknowledgements}

We thank Ryota Aoyagi, Keito Kobayashi, Susan Cordell, Elizabeth Stacy, Rebecca Ostertag, Amanda Uowolo, Tomoko Sakishima, Gary Sur, and Joshua Nagle for their supports on our fieldwork. We also thank the Department of Land and Natural Resources (DOFAW) for permission to take plant samples. This study was partly supported by grants from JSPS KAKENHI \#JP17J04193 to GA and \#15KK0255 to YO, The Kyoto University Foundation to GA, and Internship Subsidy from CoHHO (the Connectivity of Hills, Humans, and Oceans) Educational Program to GA.

\section{Introduction}

Leaf trichomes are known to influence various biophysical processes depending on their habitat conditions (Bickford, 2016; Johnson, 1975) such as increasing water-use efficiency (WUE) through increasing vapordiffusion resistance (e.g., Kenzo, Yoneda, Azani, \& Majid, 2008); maintaining leaf temperature above air temperature by decreasing sensible-heat flux (e.g., Meinzer \& Goldstein, 1985) or below air temperature by reflecting radiations (e.g., Ehleringer \& Mooney, 1978); avoiding photoinhibition by increasing light reflectance (e.g., Skelton, Midgley, Nyaga, Johnson, \& Cramer, 2012); promoting condensation on leaf surface either to decrease water loss (e.g., Konrad, Burkhardt, Ebner, \& Roth-Nebelsick, 2015) or to capture water from dew on leaf surface (e.g., Ohrui, et al. 2007). Leaf trichomes are often associated with drought tolerance because plants with densely pubescent leaves are often abundant in dry environmental conditions (Aronne \& De Micco, 2001; Ehleringer \& Mooney, 1978; Ichie, Inoue, Takahashi, Kamiya, \& Kenzo, 2016; Johnson, 1975; Moles et al., 2020; Smith \& Nobel, 1977) and because pubescent individuals have lower mortality than glabrous individuals after climatic drought events even within a species (Ando, Isagi, \& Kitayama, 2020). In addition, plants with extremely dense trichomes are also often found in alpine regions (Hedberg, 1964; Meinzer \& Goldstein, 1985), suggesting that the dense leaf trichomes could play some important roles in low-temperature conditions as well.

Dense leaf trichomes, in theory, increase diffusion resistance (i.e., decrease diffusion conductance which is the inverse of resistance) to gas and heat fluxes on the lamina surface (called as "leaf-trichome resistance" in this study; Nobel, 2009; Schuepp, 1993), which may be associated with the adaptations to both dry and low-temperature conditions. An increase in diffusion resistance on gas fluxes including $\mathrm{H}_{2} \mathrm{O}$ and $\mathrm{CO}_{2}$ can reduce both transpiration rate and photosynthetic rate. When leaf temperature is fixed, the effect of diffusion 
resistance is larger on the transpiration rate than on the photosynthetic rate, leading to greater WUE (called as "direct effect" in this study; Figure 1; Flexus et al., 2013; Schuepp, 1993). Since in many species the density of leaf trichomes is higher on leaf lower surface, where stomata exist, than on the upper surface (e.g., Aronne \& De Micco 2001; Roth, 1984), it has been believed for many years that this "direct" effect (possible higher WUE through a direct suppression of gas-exchange rates) is a major ecological advantage of leaf trichomes in dry conditions [reviewed in Bickford (2016), Johnson (1975), and Sayre (1920)]. While some previous studies supported this argument (Kenzo et al., 2008; Ripley, Pammenter, \& Smith, 1999; Wuenscher, 1970), many other studies repeatedly demonstrated that the direct effect of leaf-trichome resistance on $\mathrm{H}_{2} \mathrm{O}$ diffusion is negligible because the leaf-trichome resistance is an order of magnitude smaller than stomatal resistance (Amada, Ichie, Onoda, \& Kitayama, 2017; Benz \& Martin, 2006; Ehleringer \& Mooney, 1978; Johnson, 1975; Nobel, 2009; Sayre, 1920; Skelton, Midgley, Nyaga, Johnson, \& Cramer, 2012).

The leaf-trichome resistance can indirectly increase rather than decrease the gas diffusion through increasing leaf temperature due to reduction in the sensible-heat and the latent-heat fluxes (called as "indirect effect" in this study; Figure 1) (Campbell \& Norman, 2010; Jones, 2014). Higher leaf temperature increases the transpiration rate (Campbell \& Norman, 2010; Gate, 1968; Jones, 2014) and also can increase the photosynthetic rate especially in plants grown at a low temperature (Meinzer \& Goldstein, 1985; Parkhurst \& Loucks, 1972; Parkhurst, 1976). This is the contrary to the above-mentioned "direct effects" of leaf-trichome resistance on the gas exchanges. Whether leaf-trichome resistance increase or decrease the photosynthetic rate and the transpiration rate depends on the combination of the direct and indirect effects of diffusion resistance (called as "combined effects" in this study; Figure 1).

Relative importance of direct and indirect effects of leaf-trichome resistance, and the magnitude of their combined effects on the gas-exchange rates are subject to other leaf traits (e.g., leaf size, stomatal openness) and environmental conditions (e.g., air temperature, humidity, light intensity) (Jones 2014). Larger leaf width can increase the "boundary-layer resistance" (defined as diffusion resistance of boundary layer outside of trichome layer in this study), which reduces the fluxes of gas, latent heat and sensible heat, and low stomatal conductance directly reduces the fluxes of gas and latent heat (Campbell \& Norman, 2010; Jones, 2014). Air temperature may influence the indirect effect rather than the direct effect though modulating leaf temperature that determines the photosynthetic rate and the transpiration rate. For example, at low air temperature conditions (e.g., in high-elevational areas), both the photosynthetic rate and the transpiration rate can be greatly increased by increased leaf temperature, while at high air temperature conditions (e.g., in low-elevational areas), only the transpiration rate can be increased by increased leaf temperature since the photosynthetic rate is saturated or even decreases at a higher temperature (Figure 1b-c). In addition, environmental variations occur not only among sites but also within a day (i.e., diurnal change) which may influence the direct and indirect effects of leaf-trichome resistance on the whole-day gas-exchange rates.

To examine the combined direct and indirect effects of leaf-trichome resistance on the gas-exchange rates across environmental gradients, we studied Metrosideros polymorpha, an endemic and dominant tree species in the Hawaii Islands, which has enormous variations in the amount of leaf trichomes across a wide range of habitat environments: elevation ranges from nearly 0 to $2500 \mathrm{~m}$ asl (treeline), mean annual temperature from 5 to $25^{\circ} \mathrm{C}$, mean annual precipitation from a few hundreds to over 10,000 $\mathrm{mm} \mathrm{yr}^{-1}$, and soil age from a few decades to over four million years (Cordell, Goldstein, Mueller-Dombois, Webb, \& Vitousek, 1998; Cornwell, Bhaskar, Sack, Cordell, \& Lunch, 2007; Kitayama \& Mueller-Dombois, 1995). Leaf trichomes are mostly found on the lower surface of leaves (thus, the role of light reflectance is not likely) and their amount varies from 0 to ca $150 \mathrm{~g} \mathrm{~m}^{-2}$ (Joel, Aplet, \& Vitousek, 1994; Tsujii, Onoda, Izuno, Isagi, \& Kitayama, 2016). Glabrous individuals are often abundant in moderately wet areas, whereas pubescent individuals are more abundant in dry or high-elevation areas (Tsujii et al., 2016; Vitousek, Aplet, Turner, \& Lockwood, 1992). In particular, the individuals with the largest amount of leaf trichomes (up to $40 \%$ of leaf mass; Tsujii et al., 2016) can be found in dry alpine areas on Mauna Loa where the photosynthetic rate may be limited by low air temperature and drought (Hoof, Sack, Webb, \& Nilsen, 2008; Tsujii et al., 2016). Although Amada et al. (2017) showed that the "direct" effects of leaf-trichome resistance on WUE were negligible, they did not consider the "indirect" effects of leaf trichomes on gas exchanges through modulating leaf temperature. 
The "indirect" effect could be important especially in alpine areas where plants suffer from low temperature. In order to understand to what extent the leaf trichomes in $M$. polymorpha contribute to the carbon gain and WUE across the environmental gradient, it is necessary to examine both direct and indirect effects of the leaf-trichome resistance on the daily photosynthetic rate and the daily transpiration rate as well as on instantaneous gas-exchange rates.

This study aims to examine the combined effects of leaf-trichome resistance on gas exchanges across environmental gradients to obtain insights into ecological significances of the large variation in the amount of leaf trichomes in M. polymorpha. With this aim, we measured leaf morphological and physiological characteristics and monitored leaf temperature in field conditions across five elevational sites (100, 700, 1280, 1800 , and $2400 \mathrm{~m}$ ). Using the field-obtained values of morphological and physiological characteristics, we conducted model simulation analyses to quantify the combined effects of leaf-trichome resistance on the photosynthetic rate and the transpiration rate. We address the following three questions in relation to the function of leaf trichomes in M. polymorpha: (I) do leaf trichomes increase leaf temperature in field conditions through increasing diffusion resistance? (II) does the leaf-trichome resistance increase or decrease the daily photosynthetic rate and the daily transpiration rate at each elevational site? (III) which leaf traits and environmental conditions significantly influence the combined effects of leaf-trichome resistance on the photosynthetic rate and the transpiration rate across the elevational gradient?

\section{Materials and Methods}

\section{Study sites}

We used five sites that differed in elevation $(100,700,1280,1800,2400 \mathrm{~m})$ along the Saddle Road on the east slope of Mauna Loa on the island of Hawai'i, which were the same sites used in previous studies (Kitayama, Pattison, Cordell, Webb, \& Mueller-Dombois, 1997; Tsujiiet al ., 2015). Climate data for these sites are shown in Table 1 (Giambelluca et al ., 2014). Among the study sites, the $2400 \mathrm{~m}$ site has the coldest and driest environments because this site is above the base height of trade-wind inversion zone $(2255+-497$ m; Cao, Giambelluca, Stevens, \& Schroeder, 2007) and therefore exposed to cold dry descending air of the Hadley cell circulation. On the other hand, the $700 \mathrm{~m}$ site has the least dry stress. We established one additional site at $2000 \mathrm{~m}$ asl to determine the temperature dependence of photosynthesis in $M$. polymorpha . We measured air temperature and relative humidity at each site (TR-72WF-H, T\&D Co., Japan), and photosynthetic photon flux density (PPFD) at the $2400 \mathrm{~m}$ sites (DEFI2-L, JFE Advantec Co. Ltd., Japan) every ten minutes in September 2017.

\section{Leaf morphological and physiological traits}

To determine leaf morphological traits, we studied twenty randomly selected individuals at each elevational site. Leaf area and lengths of major and minor axes were determined from the scanned leaf images (GT-S630, EPSON, Japan) with image analysis software (Image J, National Institutes of Health, USA). "Characteristic leaf dimension", which is length of a leaf in the direction of airflow $(d)$, was calculated as the average length of the major and minor axes multiplied by 0.72 (Campbell \& Norman, 2010). We determined lamina mass and trichome mass by a shaving technique (Tsujii et al., 2016). We defined leaf mass per area (LMA) associated with lamina and trichome as laminaLMA and trichomeLMA, respectively, according to Tsujii et al. (2016) (i.e., LMA = laminaLMA + trichomeLMA). On one-half side of a mature leaf (separated by the midrib), we shaved leaf trichomes using a rubber thimble and punched out two 10-mm-diameter disks from both sides of the leaf. These leaf disks were dried at $70 \operatorname{deg} \mathrm{C}$ for three days and used for weighing with a digital scale. TrichomeLMA was calculated from the differences in dry weight between the disks with and without trichomes. We determined lamina and trichome thicknesses by a light microscope (SZX-ILLB2-100, Olympus, Japan). We excised $10 \times 3 \mathrm{~mm}$ segments from leaves and fixed them with $5 \%$ glutaraldehyde. Hand cut sections $\left(<10 \mu \mathrm{m}\right.$ thickness) were used to measure trichome thickness $\left(\delta_{\tau}\right)$ with a light microscope. Porosity and tortuosity were estimated from the trichome thickness by using the correlation between the 
porosity and the trichome thickness in M. polymorpha (Amada et al. 2017; Figure S1).

To determine the photosynthetic parameters [the maximum rate of RuBP (Ribulose-1,5-bisphosphate) carboxylation $\left(V_{c \max }\right)$ and the maximum rate of electron transport required to $\mathrm{RuBP}$ regeneration $\left(J_{\max }\right)$ ], we conducted gas-exchange measurements on ten randomly selected individuals at each elevational site with a portable photosynthesis system (LI-6400XT, LI-COR, USA) with the integrated fluorescence chamber head (chamber area $=2 \mathrm{~cm}^{2}, 6400-40$, LI-COR, USA). The measurement was done on intact leaves between 6 and $12 \mathrm{am}$ in July and August 2017. We determined $A-C_{i}$ curve by stepwise decrease of $\left[\mathrm{CO}_{2}\right]$ in the chamber from 400 to nearly $0 \mu \mathrm{mol} \mathrm{mol}{ }^{-1}$ and followed by step increase from 0 to $1800 \mu \mathrm{mol} \mathrm{mol}^{-1}$ under the saturating photon flux density for photosynthesis $\left(1000 \mu \mathrm{mol} \mathrm{m} \mathrm{m}^{-2} \mathrm{~s}^{-1}\right) . V_{c \max }$ and $J_{\max }$ were determined by fitting Eqs. S27-30 (Appendix S3; Farquhar et al. 1980) using least square method. $R_{d}$ was estimated as $0.015 V_{c \max }$ according to Collatz, Ball, Grivet, \& Berry (1991). The in vivo Rubisco kinetics parameters $\left(K_{o}, K_{c}, \Gamma^{*}\right.$ ) were taken from Bernacchi, Singsaas, Pimentel, Portis, \& Long (2001) (Table 2). The values of $V_{c m a x}$ and $J_{\max }$ at the 100,1280 , and $2400 \mathrm{~m}$ sites partially included the data from Amada et al. (2017).

To determine the temperature dependence of $V_{c m a x}$ and $J_{\max }$ and the stomatal parameters [the minimum stomatal conductance when $A=0\left(g_{0}\right)$ and the coefficient expressing sensitivity of stomatal conductance to photosynthetic rate and humidity deficit ( $a$ ); Appendix S3; Leuning 1995] in M. polymorpha, we conducted the gas-exchange measurements at four different leaf temperatures $\left(15,20,25,30{ }^{\circ} \mathrm{C}\right)$ on randomly selected ten individuals at the $2000 \mathrm{~m}$ site. We measured $V_{c \max }$ and $J_{\max }$ at each leaf temperature with the same procedure described above. Then, the activation energies for $V_{c \max }, J_{\max }$, and $R_{d}\left(H_{V c}, \Delta \Sigma, H_{j}, \Delta \Sigma_{\vartheta}\right.$, $\left.H_{R d}\right)$ and the entropy factors for $V_{c \max }$ and $J_{\max }\left(\Delta \Sigma, \Delta \Sigma_{\vartheta}\right)$ were fitted by using the modified Arrhenius models (see Eqs. S37-39 in Appendix S3; Medlyn et al. 2002). Using the sets of photosynthetic rates $(A)$ and humidity deficits $(D)$ for each individual in these measurements, the stomatal coefficients $\left(g_{0}, a\right)$ were fitted by using the stomatal-conductance model from Leuning (1995) (Eq. S22 in Appendix S3).

\section{Leaf temperature}

To explore the question I in Introduction, we conducted leaf-temperature measurements in the field conditions. To determine the effect of leaf trichomes on leaf temperature across the elevational gradient, we measured leaf temperature of both intact and trichome-shaved leaves at the four elevational sites $(700,1280$, $1800,2400 \mathrm{~m}$ ). We excluded the $100 \mathrm{~m}$ site for this measurement because the studied individuals in this site were tall and the sun-exposed leaves were out of reach $(>4 \mathrm{~m})$. We selected three individuals with typical leaf traits in each site, i.e., glabrous individuals in the $700 \mathrm{~m}$ site and pubescent individuals in the other sites. The mean trichome thickness of the three individuals was $0,0.278,0.433$, and $0.716 \mathrm{~mm}$ at 700,1280 , 1800 , and $2400 \mathrm{~m}$, respectively. We selected two sun-exposed leaves per individual and carefully shaved the leaf trichomes on either one of these two leaves by using a rubber thimble. These two leaves per each individual were close to each other and their microenvironmental conditions can be assumed to be almost same. In August 2017, we measured diurnal variations in leaf temperature of these leaves with 0.2-mm diameter copper/constantan thermocouples connected with a data logger $\left(0.1{ }^{\circ} \mathrm{C}\right.$ precision; ADL12, AsOne, Japan). The thermocouple was attached to the lower surface of the leaf. For intact leaves with leaf trichomes, the thermocouple was inserted beneath the trichome layer and in contact with the lamina. During this measurement, we also measured the air temperature and humidity (TR-72WF-H, T\&D Co. Ltd., Nagano, Japan) every ten minutes at each site.

To determine the association between trichome thickness and leaf temperature, we measured leaf temperature of both intact and trichome-shaved leaves collected at the 1800-m site where the variation in the amount of trichomes was largest (Table 3; Tsujii et al., 2016). We studied ten randomly selected individuals at the 1800 $\mathrm{m}$ site. One pair of opposite leaves that were fully exposed to sun was selected per individual, and the leaf trichomes on either one of the paired leaves were carefully shaved by using a rubber thimble. We confirmed that this trichome-shaved treatment itself did not directly affect the physiological activities such as stomatal conductance and transpiration rate through damaging stomata and cuticle layer (Figure S2). At least two days later, we measured leaf temperature on the upper surfaces of intact and trichome-shaved leaves using a radiation thermometer (0.1 degC precision; $62 \mathrm{MAX}+$, Fluke Corp., USA) between 11:30 and 12:30 for 
three times each on three sunny days in July 2016 (total nine times for each leaf; air temperature $22.0+-1.0$ $\operatorname{degC}$, PPFD $>2000 \mu \mathrm{mol} \mathrm{m-}{ }^{2} \mathrm{~s}^{1}$ ) when the solar angle was nearly vertical which minimized leaf direction effect between the paired leaves. We used the averages of nine data for each pair of leaves to analyze the association between leaf temperature and trichome thickness. After the measurements, the measured leaves were collected and used for the measurements of trichome thickness, as mentioned above.

\section{Statistical analyses}

A Kruskal-Wallis test was used to compare the values of each leaf trait (laminaLMA, trichomeLMA, lamina thickness, trichome thickness, leaf area, characteristic leaf dimension) among the elevational sites. A single regression analysis was used to analyze the association between trichome thickness and the temperature difference between intact and trichome-shaved leaves at the $1800 \mathrm{~m}$ site. For the statistical and model simulation analyses, we used the $\mathrm{R}$ statistical package (v.3.5.0; R Foundation for Statistical Computing, Vienna, Austria).

\section{Model simulations}

To explore the questions II and III in Introduction, we conducted two kinds of model calculation. First, we employed a simulation analysis to examine the effects of leaf-trichome resistance on the gas-exchange rates under diurnal environmental variations across the elevational gradient during the summer season (Appendix S5). We calculated leaf temperature, the photosynthetic rate, transpiration rate, and water-use efficiency of leaves at various trichome thicknesses $(0.0-1.0 \mathrm{~mm}$ which covers the range of field observed values in each site; Table 3) for each elevational site by using the field-obtained environmental variables (e.g., air temperature, relative humidity, PPFD, wind speed, atmosphere pressure) and leaf morphological (i.e., leaf characteristic dimension, trichome thickness) and physiological traits (i.e., $V_{c \max }, J_{\max }$, stomatal coefficient of Leuning model, temperature dependence of photosynthesis). We calculated the photosynthetic rate $(A)$, the transpiration rate $(E)$, water-use efficiency $\left(=A / E ;\right.$ WUE), and leaf temperature $\left(T_{l}\right)$ of leaves every ten minutes, and calculated the daily photosynthetic rate and daily transpiration rate as the sum of $A$ per day and the sum of $E$ per day, respectively (the models described later). The daily water-use efficiency was calculated as the daily photosynthetic rate divided by the daily transpiration rate. For the environmental variables, we used two-week field-measured air temperature and relative humidity measured at each site and photosynthetic photon flux density (PPFD) measured at the $2400 \mathrm{~m}$ site every ten minutes in September 2017. For the data of wind speed and air pressure, we took fixed values at each elevational site from Campbell \& Norman (2010) and Giambelluca et al. (2014) (see Table 1). For the leaf traits, we used characteristic leaf dimension, trichome thickness, $V_{c \max }$, and $J_{\max }$ measured at each elevational site. Since the measurements of temperature dependence of gas-exchange traits are very time consuming and logistically difficult in remote fields, we used values of the stomatal coefficient and temperature dependence of photosynthesis only at the $2000 \mathrm{~m}$ site as representative values while the temperature dependence of photosynthetic parameters may slightly differ depending on growth temperature (Hikosaka, Ishikawa, Borjigidai, Muller, \& Onoda, 2006).

Second, we employed a sensitivity analysis to examine what extent each of leaf and environmental factor influences the results of simulation analysis mentioned above. We calculated $A, E$, WUE, and $T_{l}$ by using the various combinations of leaf morphological and physiological variables (trichome thickness, characteristic leaf dimension, stomatal coefficient, $V_{c \max }$ ) and environmental variables (air temperature, relative humidity, PPFD, wind speed, atmosphere pressure). Because the results with other temperature dependence of $V_{c \max }$ and $J_{\max }$ from Kattge \& Knorr (2007) showed the trends similar to those with the temperature dependence in M. polymorpha measured at $2000 \mathrm{~m}$ site (Amada unpublished data), we used the temperature dependence in M. polymorpha in the sensitivity analysis (Table 3 ).

For these simulation and sensitivity analyses, the other physical (e.g., diffusion coefficients of air, heat, water vapor, and $\mathrm{CO}_{2}$ ) and physiological parameters (e.g., the Rubisco kinetics and the activation energy) were taken from the previous studies (see Table 2; Bernacchi et al., 2001; Campbell and Norman, 2010; Jones, 2014; Kattge \& Knorr, 2007; Leuning, 1995). The values of these measured characteristics and constant parameters used for the model simulations are listed in Table 2 and 3, respectively. In this study, trichome 
effects on the gas-exchange traits (i.e., daily photosynthetic rate, the daily transpiration rate, and the daily water-use efficiency) were expressed as follows:

, (1)

where $X_{P}$ and $X_{G}$ are the values of each daily characteristics with and without leaf-trichome resistance, respectively. Trichome effects on leaf temperature, and the gas-exchange traits were expressed as differences in the values of each physiological characteristics between with and without leaf-trichome resistance.

For both simulation and sensitivity analyses, to calculate $A, E$, and $T_{l}$ in leaves with and without leaftrichome resistance, we solved simultaneous equations (Eqs. 2-7 described below and Eqs. S1-39 in Appendix S1-3; see the programming code available in Appendix S4).

We used the steady-state energy-balance model for a single leaf consisting the net heat gain from radiation, the net sensible-heat flux, and the net latent-heat flux (see Appendix S1; Figure 1; Campbell \& Norman, 2010; Jones, 2014). In this study, we assumed that leaf trichomes decrease the conductance (i.e., increase resistance) to both gas-exchange and sensible-heat fluxes but do not influence the absorptance and emissivity of radiation because the leaf trichomes in $M$. polymorpha exist on the lower side of leaf surface (Amada et al., 2017; Hoof et al., 2007; Tsujii et al., 2016). We expressed the conductance to sensible-heat $\left(g_{H}\right)$ and water-vapor $\left(\gamma_{\nu}\right)$ fluxes including the effects of leaf-trichome resistance with an assumption that the leaf trichomes and stomata exist only on the lower side as follows (Campbell \& Norman, 2010; Jones, 2014):

where $r_{H}$ and $\rho_{\nu}$ are resistances to the sensible-heat flux and the transpiration respectively, $g_{H a}$ and $g_{H t}$ are the boundary-layer and trichome-layer conductances to the sensible-heat flux respectively, and $\gamma_{\nu_{a}}, \gamma_{\nu_{S}}$, and $\gamma_{\nu \tau}$ are the boundary-layer, stomatal, and trichome-layer conductances to the transpiration respectively. We assumed that leaf trichomes do not affect the boundary-layer conductance (outside of trichome layer) while leaf-surface roughness due to leaf trichomes could decrease boundary-layer resistance if the roughness increases turbulence (Schreuder, Brewer, \& Heine, 2001). Assuming that the air in the trichome layer is still, $g_{H t}$ and $\gamma_{\nu \tau}$ in Eqs. 2-3 can be expressed as follows (Amada et al., 2017; Benz \& Martin, 2006; Ehleringer \& Mooney, 1978; Meinzer \& Goldstein, 1985):

$,(4),(5)$

where $r_{H a}$ and $\rho_{\nu a}$ are leaf-trichome resistances to the heat and water-vapor fluxes respectively, $\rho$ is the molar density of air, $D_{H}$ and $\Delta_{\nu}$ are the heat and water-vapor diffusion coefficients in still air, $\varphi$ is porosity, $\tau$ is tortuosity, and $\delta_{\tau}$ is the thickness of trichome layer. Here we assumed that difference between $g_{H t}$ and $\gamma_{\nu \tau}$ depends just on the differences of diffusion coefficients (i.e., $D_{H}$ and $\Delta_{\nu}$ ). For leaves without leaf trichomes (glabrous leaves), $r_{H t}$ and $r_{v t}$ in Eqs. 4-5 are set to zero. Assuming that laminar flow prevails in the boundary layer, $g_{H a}$ and $\gamma_{\nu a}$ in Eqs. 4-5 are expressed as follows (Campbell \& Norman, 2010):

, (6), (7)

where $r_{H a}$ and $\rho_{\nu a}$ are the boundary-layer resistance to heat and water-vapor fluxes respectively, Re is Reynolds number, $\operatorname{Pr}$ is Prandtl number, $S c$ is Schmidt number, $d$ is characteristic leaf dimension in the direction of airflow, and 1.4 is a coefficient for the effect of air turbulence (Campbell \& Norman, 2010). In these parameters, $\rho, D_{H}$, and $\Delta_{\nu}$ depend on the values of temperature and pressure at each site (see Appendix S2; Campbell \& Norman, 2010). Calculations of the dimensionless numbers (Re, $P r, S c$ ) were described in Appendix S2.

When the stomatal conductance to $\mathrm{H}_{2} \mathrm{O}$ flux $\left(g_{v s}\right)$ in Eq. 3 is given, leaf temperature $\left(T_{l}\right)$ can be calculated by the combination of Eqs. 2-7 and energy balance model (see Appendix S3; Campbell and Norman, 2010). The stomatal conductance to $\mathrm{CO}_{2}$ flux $\left(g_{c s}\right)$ was calculated by using the stomatal-conductance model (see 
Appendix S3; Leuning, 1995). To calculate the photosynthetic rate, we employed the $\mathrm{C}_{3}$ biochemical model for photosynthesis according to Farquhar et al. (1980) and Medlyn et al. (2002) (see Appendix S3).

\section{Results}

\section{Leaf morphological and physiological traits}

LaminaLMA, trichomeLMA, lamina thickness, trichome thickness, leaf area, and characteristic leaf dimension were significantly different among the elevational sites (Table 3). TrichomeLMA was highest at the $2400 \mathrm{~m}$ site which was most cold-and-dry among the study sites, and lowest at the $700 \mathrm{~m}$ site which was wettest, while laminaLMA increased linearly with the elevation (Table 3). Trichome and lamina thickness showed similar patterns to trichomeLMA and laminaLMA across the elevation, respectively (Table 3). The largest values of trichomeLMA (203.7 $\mathrm{g} \mathrm{m}^{-2}, 45 \%$ of dry leaf mass) and trichome thickness $(0.776 \mathrm{~mm})$ were observed at the $2400 \mathrm{~m}$ site. Contrary to the pattern of trichomeLMA across the elevation, the leaf area was lowest at the $2400 \mathrm{~m}$ site and highest at the $700 \mathrm{~m}$ site (Table 3 ). These patterns were consistent with the previous study (Tsujii et al., 2016).

\section{Leaf temperature and environmental conditions}

In all sites, leaf temperature was usually higher than the air temperature in daytime, but lower than the air temperature in the night due to radiative cooling (Figure 2a,c,e,g, and S4). While the leaf temperature varied greatly along time, the leaf temperature tended to be consistently higher in intact pubescent leaves than in trichome-shaved leaves at the 2400, 1800, and $1280 \mathrm{~m}$ sites. In the $700 \mathrm{~m}$ site where leaf trichomes are least abundant, glabrous leaves were used for the measurement and thus leaf temperature did not differ between shaved and non-shaved leaves (Figure 2). The amount of leaf trichomes was largest and its effect on leaf temperature was largest in the $2400 \mathrm{~m}$ site on average ca. $2.0{ }^{\circ} \mathrm{C}$ increase (Table 3; Figure $2 \mathrm{~b}$ ). In the sunny morning, leaf temperature was sometimes lower in the intact pubescent leaves than in trichome-shaved leaves (Day 1 at the 2400 and $1280 \mathrm{~m}$ sites, Day 3 at the $1800 \mathrm{~m}$ site; Figure 2b,d,f) because the dense and wooly leaf trichomes in M. polymorpha prolonged the duration of leaf wetness (Amada, unpublished data), and thus increased latent-heat flux. Relative humidity was usually nearly $100 \%$ at night and decreased to ca. $60 \%$ at daytime at the 1800, 1280, and $700 \mathrm{~m}$ sites (Figure 2c,e,g). On the other hand, at the $2400 \mathrm{~m}$ site, relative humidity often showed the opposing diurnal pattern; that is, relative humidity reached ca. $20 \%$ at night and increased at daytime (18 days in August 2017). This was probably due to the cool-dry-nighttime drainage winds originating above the trade-wind inversion while in the daytime upslope winds bring moist marine-surface air (Nullet, Juvik, \& Wall, 1995).

When we compared leaves with different thickness of leaf trichomes in a given site (1800 $\mathrm{m}$ site), the difference in leaf temperature between intact and trichome-shaved leaves was significantly larger in leaves with higher trichome thickness (Figure 3).

\section{Effects of leaf-trichome resistance on gas exchanges}

Our simulation analysis based on field-obtained leaf traits at each site shows that leaf temperature was consistently higher than the ambient air temperature in daytime across all elevational sites (Figure 4a,c,d). While daytime leaf temperature can be higher than air temperature for a number of reasons other than leaf trichomes (i.e., leaf size, transpiration, PPFD), leaf-trichome resistance itself actually increased leaf temperature under the daytime conditions especially in leaves with thicker leaf trichomes (Figure $4 \mathrm{~g}$ ). In daytime, the effect of leaf-trichome resistance was consistently much greater on sensible-heat flux than $\mathrm{H}_{2} \mathrm{O}$ flux across the elevational gradient (e.g., $7.6 \%$ for $\mathrm{H}_{2} \mathrm{O}$-flux resistance and $45.1 \%$ for the sensible-heat-flux resistance at the $2400 \mathrm{~m}$ site on average; Figure 5a-c), which strongly influences the gas-exchange rates through the "indirect" effect (Figure 1). For carbon budgets, leaf-trichome resistance slightly increased the daily photosynthetic rates at the 1800 and $2400 \mathrm{~m}$ sites $(+0.1 \%$ and $+0.8 \%$, respectively) but decreased it in the other sites (-1.1--0.4\%; Figure 4e,h, and 5d,g). For water budgets, leaf-trichome resistance slightly 
decreased the daily transpiration rates only at the $100 \mathrm{~m}$ site $(-0.2 \%)$ but increased it in the other sites $(+0.2-$ +5.2 ; Figure 4f,i, and 5e,g). Leaf-trichome resistance consistently decreased the daily water-use efficiency in all study sites due to either increased water loss (the $2400 \mathrm{~m}$ site) or suppressed photosynthesis (the $150 \mathrm{~m}$ site) or both (the 700, 1280, and $1800 \mathrm{~m}$ sites) (Figure 5). Across various trichome thickness (from 0 to $1 \mathrm{~mm}$ at $0.05 \mathrm{~mm}$ intervals), the effects of leaf-trichome resistance on $\mathrm{H}_{2} \mathrm{O}$ and sensible-heat fluxes monotonically increased (Figure 6a,b) and the differences in leaf temperature between with and without leaf-trichome resistance became monotonically wider at all sites (Figure 6c,d). On the other hand, with increasing trichome thickness, the effect of leaf-trichome resistance on the daily photosynthetic rate showed an upward-convex curve at the $2400 \mathrm{~m}$ site (Figure 6e), and the daily photosynthetic rates can be enhanced only at the $2400 \mathrm{~m}$ site when trichome thickness was up to $0.8 \mathrm{~mm}$ which is similar to the largest trichome thickness observed in this study $(0.776 \mathrm{~mm})$. At the other sites, the daily photosynthetic rates were reduced by leaf-trichome resistance in any trichome thickness (Figure 6e). The daily transpiration rates showed an upward-convex curve across trichome thickness at all sites except for the $100 \mathrm{~m}$ site where the daily transpiration rates were consistently reduced by leaf-trichome resistance (Figure 6f). The daily transpiration rates can be enhanced by leaf-trichome resistance in any trichome thickness from 0 to $1 \mathrm{~mm}$ at the 1280, 1800, and $2400 \mathrm{~m}$ sites (Figure 6f). The daily water-use efficiency was consistently suppressed by leaf-trichome resistance with any trichome thickness across all sites (Figure 6g).

In the second analysis, we conducted the sensitivity analysis on the effects of leaf trichomes on the photosynthetic rate $(A)$, the transpiration rate $(E)$, the water-use efficiency (WUE), leaf temperature $\left(T_{l}\right)$ with varying environmental factors (air temperature, relative humidity, PPFD, wind speed, and atmosphere pressure) and other leaf traits (characteristic leaf dimension, stomatal coefficient, and $V_{\text {cmax }}$ ) (Figure S5$8)$. The effects of leaf-trichome resistance on the gas-exchange rates strongly depend on air temperature $\left(T_{a}\right)$, relative humidity $(h), \operatorname{PPFD}(Q)$, characteristic leaf dimension $(d)$, and stomatal coefficient $(a$ ) as well as on trichome thickness $\left(\delta_{\tau}\right)$ but not on wind speed, atmosphere pressure, and $V_{\text {cmax }}$ (Figure S5-8); thus, we henceforth focus on the six factors: $T_{a}, h, Q, d, a$, and $\delta_{\tau}$. In order to visualize these complex interactions, we employed two kinds of heatmaps to present how the gas-exchange rates depend on those environmental factors and leaf traits, and also to present how the effects of leaf-trichome resistance on the gas-exchange rates depend on those environmental factors and leaf traits (Figure 7). First, we draw a heatmap of the photosynthetic rates across various characteristic leaf dimension and trichome thickness at a given combination of other variables (air temperature, relative humidity, PPFD, and stomatal coefficient). Figure $7 \mathrm{a}$ is such example, the photosynthetic rates are expressed across varying characteristic leaf dimension and trichome thickness at a condition of $T_{a}=15{ }^{\circ} \mathrm{C}, h=0.8, Q=2400 \mu \mathrm{mol} \mathrm{m}{ }^{-2} \mathrm{~s}^{-1}, a=2.5$. Similar heatmaps are made for all combinations of air temperature $\left(T_{a}=5,10,15,20,25,30,35^{\circ} \mathrm{C}\right)$ and $\operatorname{PPFD}(Q$ $\left.=300,600,1200,2400 \mu \mathrm{mol} \mathrm{m} \mathrm{s}^{-1}\right)$ at fixed stomatal coefficient $(a=2.5$; isohydric leaves. relevant for $M$. polymorpha ) and relative humidity (Figure 7c). In order to visualize the effect of leaf-trichome resistance on the photosynthetic rates, we draw another heatmap which shows absolute differences in the photosynthetic rates between leaves with trichomes $\left(\delta_{\tau}=0.05-1.00 \mathrm{~mm}\right.$ in Figure $\left.7 \mathrm{a}\right)$ and leaves without trichomes $\left(\delta_{\tau}\right.$ $=0 \mathrm{~mm}$ in Figure 7a) (Figure $7 \mathrm{~b}$ ). Figure $7 \mathrm{~b}$ is such example where orange and navy colors mean that the leaf-trichome resistance increases and decreases the photosynthetic rates respectively. Similar heatmaps are made for all combinations of air temperature and PPFD (Figure 7d). In Figure 7a-b, points and bars represent the means and standard deviations of field-observed trichome thickness and characteristic leaf dimension at each site. Furthermore, these analyses are also made for the transpiration rate and water-use efficiency at three values of stomatal coefficient $(a=2.5,5,10)$ (Figure 8). Sensitivity analyses in relation to other relative humidity $(h=0.2,0.5)$ are available in Figure S9-10.

At low stomatal coefficient ( $a=2.5$; Figure 8a,d,g; isohydric leaves) that may represent the stomatal behaviors of $M$. polymorpha (Table 3), leaf-trichome resistance tends to decease the photosynthetic rate $(A$ ) when air temperature is more than $15{ }^{\circ} \mathrm{C}$, but it increases $A$ at low air temperature (Figure 8a). In relation to characteristic leaf dimension, leaf-trichome resistance tends to increase $A$ in smaller characteristic leaf dimension (Figure 8a). For water budgets, the leaf-trichome resistance tends to decrease the transpiration rate $(E)$ at middle air temperature $\left(15-30{ }^{\circ} \mathrm{C}\right)$ though it tends to increase $E$ at high PPFD and low air 
temperature (Figure 8d). The leaf-trichome resistance tends to increase $E$ in leaves with smaller characteristic leaf dimension (Figure 8d). Overall, the leaf-trichome resistance tends to increase the water-use efficiency (WUE) under low light and low air temperature but tends to decrease it under high light and high air temperature (Figure 8g). The leaf-trichome resistance in leaves with smaller characteristic leaf dimension tends to decrease WUE (Figure $8 \mathrm{~g}$ ). The magnitudes of effects of leaf-trichome resistance on $A, E$, and WUE tend to increase with increasing trichome thickness (Figure 8). Among different humidity conditions, humidity, the effects of leaf-trichome resistance on $A, E$, and WUE does not differ so much (Figure 8 and S9-10).

In order to explore the roles of leaf trichomes in wider context (i.e., considering other plant species), we also conducted similar sensitivity analyses with higher stomatal coefficients $(a=5,10$; Figure 8; more anisohydric leaves). With higher stomatal coefficient, the leaf-trichome resistance tends to increase $A$, decrease $E$, and increase WUE compared to lower stomatal coefficient (Figure 8). However, the values of WUE themselves are much higher in leaves with lower stomatal coefficient than in leaves with higher stomatal coefficient (Figure $8)$.

\section{Discussion}

\section{Leaf temperature and leaf trichome}

In all field sites across the elevation gradient, leaf temperature was higher than the air temperature in daytime (Figure 2b,f, and S4) where leaf trichomes were partly responsible for this increase (Figure 3). Thicker leaf trichomes decreased the sensible-heat and latent-heat fluxes through higher leaf-trichome resistance (Meinzer \& Goldstein, 1985). While some studies argued or suggested that leaf trichomes could increase heat dissipation through increasing turbulence in the boundary layer (Schreuder et al., 2001) or through increasing the effective heat-transfer surface area like cooling fins (Baldocchi, Singsaas, Pimentel, Portis, \& Long, 1983; Defraeye, Verboven, Ho, \& Nicolai, 2013), our study suggested that the dense leaf trichomes in $M$. polymorpha had greater effects as heat resistance rather than as heat dissipation.

In both field measurements and simulation analyses, the effects of leaf trichome on leaf temperature were largest in the coldest and driest site (Figure 2, 4g) where the amount of leaf trichomes was largest (Table 3; Joel et al. 1994; Tsujii et al. 2016). The magnitudes of these effects tended to be greater in the field measurements than in the simulation analyses: for example, leaf trichomes with 0.5-mm thickness can increase leaf temperature over $3 \mathrm{deg} C$ in the field conditions (Figure 3) but ca. $1.8 \operatorname{deg} \mathrm{C}$ in simulation analyses (Figure 6d). The difference of these effects between the actual conditions and the simulation is possibly due to other factors that we did not consider in the simulation analyses, such as, roles of leaf trichomes other than diffusion resistance including their heat storage. Regardless other factors that may influence the leaf temperature, the similar trends between the actual values and simulated results indicate that major effects of leaf-trichome resistance on the gas-exchange rates are covered by our model.

The largest effects of leaf trichomes on the sensible-heat flux and leaf temperature in the coldest and driest site were attributable not only to the largest trichome thickness but also to the smallest leaf size (Table 3; Figure $4 \mathrm{~g}$ and 5c). A smaller leaf, i.e., a smaller characteristic leaf dimension, have lower boundary-layer resistance (Eqs. 6-7; Nobel, 2009; Schuepp, 1993). Since sensible-heat resistance is considered as a sum of the leaf-trichome and boundary-layer resistance (Eq. 2), the relative effects of leaf trichomes is greater in smaller leaves for a given trichome thickness (Figure 6b). As seen in alpine ecotypes of $M$. polymorpha, many alpine plants typically have small leave (Halloy \& Mark, 1996; Korner, Neumayer, Menendez-Riedl, \& Smeets-Scheel, 1989; Tsujii et al. 2016; Wright et al., 2017); therefore, having leaf trichomes in alpine regions may be particularly beneficial as increase in leaf temperature with leaf trichomes can be more pronounced in smaller leaves.

Ecological significance of leaf trichomes as diffusion resistance 
As we demonstrated that the leaf trichomes in M. polymorphasubstantially influenced the leaf heat balance both in the field conditions and in the simulation analyses. This means that the indirect effects on the photosynthetic and transpiration rates through changing leaf temperature cannot be ignored (Figure 1).

The photosynthetic rates were increased by leaf trichomes only at the high-elevational sites and decreased at the other lower-elevational sites (Figure 4h). This different trend is mainly due to the non-linear response of photosynthetic rates to temperature (Figure 8). In cold alpine environments the increase in leaf temperature with leaf-trichome resistance can increase the activity of photosynthetic enzymes; thus, the leaf trichomes can increase the photosynthetic rate (Meinzer \&Goldstein, 1985; Parkhurst \& Loucks, 1972; Parkhurst, 1976). On the other hand, in warm low-elevational environments, the increase in leaf temperature dose not increase or even decreases the photosynthetic rate (Parkhurst \& Loucks, 1972; Parkhurst, 1976) due to enhanced respiration as well as photorespiration (Hofstra \& Hesketh, 1969; Long 1991).

The increase in the whole-day carbon gain with the leaf trichomes seem to be modest $(+0.8 \%)$ for the large amount of leaf trichomes (up to $45 \%$ of leaf mass). In the model simulation, since we used the environmental variations during summer season on the island of Hawaii (in September), the effect of leaf trichomes on the carbon gain can be even greater at lower-temperature conditions (Figure 8) during a winter season: monthly mean temperature in the 2400 site ranges from $7.0 \mathrm{deg} C$ in February to $10.6 \mathrm{degC}$ in August (Giambelluca et al., 2014). Because the pubescent leaves at the high-elevational site have long lifespan (ca. six years; Amada et al., 2017), such marginal carbon gain may accumulate and recover the large carbon investment in trichomes throughout the leaf lifespan. Moreover, the increased leaf temperature might also increase the photosynthesis through other physiological processes including leaf developments and hydraulic traits which is strongly depend on leaf temperature (Sack, Melcher, Zwieniecki, \& Holbrook, 2002; Sack, Streeter, \& Holbrook, 2004).

The leaf trichomes consistently decreased rather than increased the whole-day water-use efficiency (WUE) at all elevational sites (Figure 5g) across a range of trichome thickness (0.05-1 mm; Figure 6g); therefore, the hypothesis that leaf trichomes as diffusion resistance play a role in higher WUE (Bickford, 2016; Johnson, 1975; Kenzo et al., 2008; Ripley et al., 1999; Wuenscher, 1970) cannot be supported in M. polymorpha . This is mainly due to the strong-irradiance conditions in Hawaii (Figure 4b) and also due to the differences in temperature dependence between the photosynthetic rate and the transpiration rate (Figure 1b-c). The strong irradiance increases the heat gain of leaves, under which the sensible-heat flux is greatly suppressed by leaf trichomes; thus, further increases leaf temperature. Moreover, relative increase in the transpiration rates is faster than that of the photosynthetic rates with increase in leaf temperature (Figure 1 and 8). A similar logic can be applied to effects of leaf size on WUE through boundary-layer resistance, that is, larger leaves with greater boundary-layer resistance decrease WUE under strong-irradiance dry conditions (Parkhurst \& Loucks, 1972; Okajima et al., 2012). Therefore, leaf trichomes cannot contribute to drought tolerance through increasing diffusion resistance if both direct and indirect effects are considered.

Since leaf trichomes are observed in the wide range of plant taxa (Ichie et al., 2016; Johnson, 1975), we also explore the roles of leaf trichomes for more anisohydric plants than $M$. polymorpha (Table 3; Cornwell et al., 2007; Amada et al., 2017). Our sensitivity analyses show that leaf trichomes can increase WUE for anisohydric leaves located in low-temperature conditions or for leaves located in low-irradiance conditions (Figure 8h,i). However, these leaf traits and environmental conditions are not the conditions where pubescent plants are found. Stomatal behavior tends to be conservative in the stressful environments where pubescent plants often exist, such as arid areas, strong-irradiative areas, high-elevational areas, windswept conditions, and dry seasons (Agrawal et al., 2009; Aronne \& De Micco, 2001; Ehleringer, 1981; Ichie et al., 2016; Johnson, 1975; Moles et al., 2020; Smith \& Nobel, 1977; Tsujii et al., 2016). Indeed, WUE itself is much greater in more isohydric leaves than in anisohydric leaves (Figure 8g,h,i, and S11); thus, stomatal regulation is more effective to improve WUE than increases leaf-trichome resistance. In a tropical forest, trees exposed to the strong irradiance (canopy trees and gap plants) tend to have greater trichome density than understory or subcanopy trees (Ichie et al., 2016). Therefore, we do not consider the diffusion resistance as the primary function of leaf trichomes against dry stresses even in other pubescent plant species. 
Leaf trichomes may have other functions in relation to drought tolerance (Johnson 1975; Bickford, 2016) such as defense against herbivores to avoid extra water loss (Amada et al., 2020) and promoting condensation on leaf surface either to decrease water loss (e.g., Konrad et al ., 2015) or to uptake water from dew on leaf surface (e.g., Ohrui et al., 2007). Amada et al. (2020) suggested that leaf trichomes in M. polymorpha can impede gall formation of specialist psyllids that increases water stress in leaves. Moreover, leaf trichomes in M. polymorpha often get wet even in the coldest and driest alpine areas (Amada, unpublished data), which may improve leaf water status. To understand the extreme variation of leaf trichomes in M. polymorpha, still some further work may be needed to evaluate ecological significance of multifunctional leaf trichomes against various environmental stresses (Sack \& Buckley, 2020).

\section{Conclusion}

To our knowledge, this is a first study to quantify the combined direct and indirect effects of leaf-trichome resistance on the gas-exchange rates across a wide range of environmental gradients. The large amount of leaf trichomes in $M$. polymorpha can increase diffusion resistance on the leaf surface and contribute to higher carbon gain through increasing leaf temperature in alpine conditions. In addition, this trichome effects are enhanced by smaller leaves which are typically found in alpine plants. On the other hand, leaf trichomes cannot increase the carbon gain in other lower sites partly because the photosynthetic rates are not sensitive to small increase in leaf temperature in warmer areas.

Leaf trichomes can have adverse effects on WUE at all study sites, primarily because leaf trichomes can greatly increase leaf temperature in $M$. polymorpha (strong isohydric species inhabiting strong-irradiance conditions) and higher leaf temperature results into increase in the transpiration rates more than increase in the photosynthetic rates. Our sensitivity analyses show that leaf trichomes could enhance WUE in more anisohydric leaves inhabiting low-temperature conditions or in leaves inhabiting low-irradiance conditions, but these conditions are not typical conditions where dense pubescent plants are found. Therefore, we do not support the hypothesis that leaf trichomes contribute to drought tolerance through increasing diffusion resistance.

\section{Acknowledgements}

We thank Ryota Aoyagi, Keito Kobayashi, Susan Cordell, Elizabeth Stacy, Rebecca Ostertag, Amanda Uowolo, Tomoko Sakishima, Gary Sur, and Joshua Nagle for their supports on our fieldwork. We also thank the Department of Land and Natural Resources (DOFAW) for permission to take plant samples. This study was partly supported by grants from JSPS KAKENHI \#JP17J04193 to GA and \#15KK0255 to YO, and Internship Subsidy from CoHHO (the Connectivity of Hills, Humans, and Oceans) Educational Program to GA.

\section{References}

Agrawal, A. A., Fishbein, M., Jetter, R., Salminen, J. P., Goldstein, J. B., Freitag, A. E., \& Sparks, J. P. (2009). Phylogenetic ecology of leaf surface traits in the milkweeds (Asclepias spp.): chemistry, ecophysiology, and insect behavior. New Phytologist, 183, 848-867.

Amada, G., Onoda, Y., Ichie, T., \& Kitayama, K. (2017). Influence of leaf trichomes on boundary layer conductance and gas-exchange characteristics in Metrosideros polymorpha (Myrtaceae).Biotropica , 49, 482492. 
Amada, G., Kobayashi, K., Izuno, A., Mukai, M., Ostertag, R., Kitayama, K., \& Onoda, Y. (2020). Leaf trichomes in Metrosideros polymorpha can contribute to avoiding extra water stress by impeding gall formation. Annals of Botany , 125, 533-542.

Ando, S., Isagi, Y., \& Kitayama, K. Genecology and ecophysiology of the maintenance of foliar phenotypic polymorphisms of Leptospermum recurvum (Myrtaceae) under oscillating atmospheric desiccation in the tropical-subalpine zone of Mount Kinabalu, Borneo. Ecological Research, in press.

Aronne, G., \& De Micco, V. (2001). Seasonal dimorphism in the Mediterranean Cistus incanus L. subsp. incanus .Annals of Botany , 87, 789-794.

Benz, B. W., \& Martin, C. E. (2006). Foliar trichomes, boundary layers, and gas exchange in 12 species of epiphytic Tillandsia (Bromeliaceae). Journal of plant physiology , 163, 648-656.

Bernacchi, C. J., Singsaas, E. L., Pimentel, C., Portis, Jr. A. R., \& Long, S. P. (2001). Improved temperature response functions for models of Rubisco-limited photosynthesis. Plant, Cell \& Environment, 24, 253-259.

Bickford, C. P. (2016). Ecophysiology of leaf trichomes.Functional Plant Biology, 43, 807-814.

Britton, C. M., \& Dodd, J. D. (1976). Relationships of photosynthetically active radiation and shortwave irradiance.Agricultural Meteorology, 17, 1-7.

Campbell, G. S., \& Norman, J. M. (1998). An introduction to environmental biophysics. USA: SpringerVerla.

Cao, G., Giambelluca, T. W., Stevens, D. E., \& Schroeder, T. A. (2007). Inversion variability in the Hawaiian trade wind regime. Journal of Climate, 20, 1145-1160.

Collatz, G. J., Ball, J. T., Grivet, C., \& Berry, J. A. (1991). Physiological and environmental regulation of stomatal conductance, photosynthesis and transpiration: a model that includes a laminar boundary layer. Agricultural and Forest meteorology, 54, 107-136.

Cordell, S., Goldstein, G., Mueller-Dombois, D., Webb, D., \& Vitousek, P. M. (1998). Physiological and morphological variation in Metrosideros polymorpha, a dominant Hawaiian tree species, along an altitudinal gradient: The role of phenotypic plasticity. Oecologia , 113, 188-196.

Cornwell, W.K., Bhaskar, R., Sack, L., Cordell, S., \& Lunch, C. K. (2007). Adjustment of structure and function of Hawaiian Metrosideros polymorpha at high vs. low precipitation. Functional Ecology , 21, 1063-1071.

Crausbay, S. D., Frazier, A. G., Giambelluca, T. W., Longman, R. J., \& Hotchkiss, S. C. (2014). Moisture status during a strong El Nino explains a tropical montane cloud forest's upper limit. Oecologia , 175, $273-284$.

Defraeye, T., Verboven, P., Ho, Q. T., \& Nicolai, B. (2013). Convective heat and mass exchange predictions at leaf surfaces: Applications, methods and perspectives.Computers and Electronics in Agriculture , 96, $180-201$.

Ehleringer, J., Bjorkman, O., \& Mooney, H. A. (1976). Leaf pubescence: effects on absorptance and photosynthesis in a desert shrub.Science, 192, 376-377.

Ehleringer, J. R., \& Bjorkman, O. (1978). Pubescence and leaf spectral characteristics in a desert shrub, Encelia farinosa .Oecologia , 36, 151-162.

Ehleringer, J. R., \& Mooney, H. A. (1978). Leaf hairs: effects on physiological activity and adaptive value to a desert shrub.Oecologia, 37, 183-200.

Farquhar, G. D., von Caemmerer, S., \& Berry, J. A. (1980). A biochemical model of photosynthetic $\mathrm{CO}_{2}$ assimilation in leaves of C3 species. Planta, 149, 78-90. 
Flexas, J., Niinemets, U., Galle, A., Barbour, M. M., Centritto, M., Diaz-Espejo, A., .. \& Medrano, H. (2013). Diffusional conductances to $\mathrm{CO}_{2}$ as a target for increasing photosynthesis and photosynthetic water-use efficiency. Photosynthesis Research , 117, 45-59.

Gates, D. M. (1968). Transpiration and leaf temperature. Annual Review of Plant Physiology, 19, 211-238.

Giambelluca, T. W., Shuai, X., Barnes, M. L., Alliss, R. J., Longman, R. J., Miura, T., .. \& Businger. A.D. (2014). Evapotranspiration of Hawai'i. Final report submitted to the U.S. Army Corps of EngineersHonolulu District, and the Commission on Water Resource Management, State of Hawai'i.

Gibbs, J. G., \& Patten, D. T. (1970). Plant temperatures and heat flux in a Sonoran Desert ecosystem. Oecologia , 5, 165-184.

Halloy, S. R. P., \& Mark, A. F. (1996). Comparative leaf morphology spectra of plant communities in New Zealand, the Andes and the European Alps. Journal of the Royal Society of New Zealand, 26, 41-78.

Hedberg, O. (1964). Features of Afroalpine plant ecology. Sweden: Almqvist \& Wiksen.

Hikosaka, K., Ishikawa, K., Borjigidai, A., Muller, O., \& Onoda, Y. (2006). Temperature acclimation of photosynthesis: mechanisms involved in the changes in temperature dependence of photosynthetic rate. Journal of experimental botany , 57, 291-302.

Hofstra, G., \& Hesketh, J. D. (1969). Effects of temperature on the gas exchange of leaves in the light and dark. Planta, 85, 228-237.

Hoof, J., Sack, L., Webb, D. T., \& Nilsen, E. T. (2008). Contrasting structure and function of pubescent and glabrous varieties of Hawaiian Metrosideros polymorpha(Myrtaceae) at high elevation. Biotropica , 40, $113-118$.

Ichie, T., Inoue, Y., Takahashi, N., Kamiya, K., \& Kenzo, T. (2016). Ecological distribution of leaf stomata and trichomes among tree species in a Malaysian lowland tropical rain forest. Journal of plant research 129: 625-635.

Joel, G., Aplet, G., \& Vitousek, P. M. (1994). Leaf morphology along environmental gradients in HawaiianMetrosideros polymorpha. Biotropica , 26, 17-22.

Johnson, H. B. (1975). Plant pubescence: An ecological perspective. The Botanical Review , 41, 233-258.

Jones, H. G. (2014). Plants and microclimate: a quantitative approach to environmental plant physiology . UK: Cambridge University Press.

Kattge, J., \& Knorr, W. (2007). Temperature acclimation in a biochemical model of photosynthesis: a reanalysis of data from 36 species. Plant, cell $\&$ environment, 30, 1176-1190.

Kenzo, T., Yoneda, R., Azani, M. A., \& Majid, N. M. (2008). Changes in leaf water use after removal of leaf lower surface hairs onMallotus macrostachyus (Euphorbiaceae) in a tropical secondary forest in Malaysia. Journal of Forest Research , 13, 137-142.

Kitayama, K., \& Mueller-Dombois, D. (1995). Vegetation changes along gradients of long-term soil development in the Hawaiian montane rainforest zone. Vegetation , 120, 1-20.

Kitayama, K., Pattison, R., Cordell, S., Webb, D., \& Mueller-Dombois, D. (1997). Ecological and genetic implications of foliar polymorphism in Metrosideros polymorpha Gaud. (Myrtaceae) in a habitat matrix on Mauna Loa, Hawaii. Annals of Botany , 80, 491-497.

Korner, C., Neumayer, M., Menendez-Riedl, S. P., \& Smeets-Scheel, A. (1989). Functional morphology of mountain plants. Flora, 182, 353-383.

Konrad, W., Burkhardt, J., Ebner, M., \& Roth-Nebelsick, A. (2015). Leaf pubescence as a possibility to increase water use efficiency by promoting condensation. Ecohydrology , 8, 480-492. 
Leuning, R. (1995). A critical appraisal of a combined stomatal-photosynthesis model for C3 plants. Plant, Cell \& Environment, 18, 339-355.

Long, S. P. (1991). Modification of the response of photosynthetic productivity to rising temperature by atmospheric $\mathrm{CO}_{2}$ concentrations: has its importance been underestimated? Plant, Cell \& Environment, 14, $729-739$.

Medlyn, B. E., Dreyer, E., Ellsworth. D. S., Forstreuter, M., Harley, P. C., Kirschbaum, M. U. F., .. \& \& Loustau, D. (2002). Temperature response of parameters of a biochemically based model of photosynthesis. II. A review of experimental data. Plant, Cell $\& 3$ Environment , 25, 1167-1179.

Meinzer, F., \& Goldstein, G. (1985). Some consequences of leaf pubescence in the Andean giant rosette plant Espeletia timotensis . Ecology , 66, 512-520.

Moles, A. T., Laffan, S. W., Keighery, M., Dalrymple, R. L., Tindall, M. L., \& Chen, S. C. (2020). A hairy situation: Plant species in warm, sunny places are more likely to have pubescent leaves. Journal of Biogeography . doi: https://doi.org/10.1111/jbi.13870

Nobel, P. S. (2009). Physicochemical and environmental plant physiology . USA: Elsevier Academic Press.

Nullet, D., Juvik, J. O., \& Wall, A. (1995). A Hawaiian mountain climate cross-section. Climate Research, $5,131-137$.

Ohrui, T., Nobira, H., Sakata, Y., Taji, T., Yamamoto, C., Nishida, K., .. \& Tanaka, S. (2007). Foliar trichome-and aquaporin-aided water uptake in a drought-resistant epiphyte Tillandsia ionanthaPlanchon. Planta , 227, 47-56.

Okajima, Y., Taneda, H., Noguchi, K., \& Terashima, I. (2012). Optimum leaf size predicted by a novel leaf energy balance model incorporating dependencies of photosynthesis on light and temperature.Ecological research , 27, 333-346.

Parkhurst, D. F., \& Loucks, O. L. (1972). Optimal leaf size in relation to environment. The Journal of Ecology , 505-537.

Parkhurst, D. F. (1976). Effects of Verbascum thapsus leaf hairs on heat and mass transfer: a reassessment. New Phytologist , 76, 453-457.

Ripley, B. S., Pammenter, N. W., \& Smith, V. R. (1999). Function of leaf hairs revisited: the hair layer on leaves Arctotheca populifolia reduces photoinhibition, but leads to higher leaf temperatures caused by lower transpiration rates. Journal of Plant Physiology , 155, 78-85.

Roth, I. (2012). Stratification of tropical forests as seen in leaf structure (Vol. 6). Springer Science \& Business Media.

Sack, L., Melcher, P. J., Zwieniecki, M. A., \& Holbrook, N. M. (2002). The hydraulic conductance of the angiosperm leaf lamina: a comparison of three measurement methods. Journal of experimental botany, 53, $2177-2184$.

Sack, L., Streeter, C. M., \& Holbrook, N. M. (2004). Hydraulic analysis of water flow through leaves of sugar maple and red oak. Plant Physiology , 134, 1824-1833.

Sack, L., \& Buckley, T. N. (2020). Trait multi-functionality in plant stress response. Integrative and comparative biology, 60, 98-112.

Sayre, J. D. (1920). The relation of hairy leaf coverings to the resistance of leaves to transpiration. The Ohio Journal of Science, 20, 55-86.

Schreuder, M. D., Brewer, C. A., \& Heine, C. (2001). Modelled influences of non-exchanging trichomes on leaf boundary layers and gas exchange. Journal of Theoretical Biology , 210, 23-32. 
Schuepp, P. H. (1993). Tansley Review No. 59. Leaf boundary layers.New Phytologist , 125, 477-507.

Skelton, R. P., Midgley, J. J., Nyaga, J. M., Johnson, S. D., \& Cramer, M. D. (2012). Is leaf pubescence of Cape Proteaceae a xeromorphic or radiation-protective trait? Australian Journal of Botany , 60, 104-113.

Smith, W. K., \& Nobel, P. S. (1977). Influences of seasonal changes in leaf morphology on water-use efficiency for three desert broadleaf shrubs. Ecology , 58, 1033-1043.

Tsujii, Y., Onoda, Y., Izuno, A., Isagi, Y., \& Kitayama, K. (2016). A quantitative analysis of phenotypic variations of Metrosideros polymorpha within and across populations along environmental gradients on Mauna Loa, Hawaii. Oecologia, 180, 1049-1059.

Vitousek, P. M., Aplet, G., Turner, D., \& Lockwood, J. J. (1992). The Mauna Loa environmental matrix: foliar and soil nutrients. Oecologia , 89, 372-382.

Walker, A. P., Beckerman, A. P., Gu, L., Kattge, J., Cernusak, L. A., Domingues, T. F., .. \& Woodward, F. I. (2014). The relationship of leaf photosynthetic traits- $V_{c \max }$ and $J_{\max }$-to leaf nitrogen, leaf phosphorus, and specific leaf area: a meta-analysis and modeling study. Ecology and evolution, 4, 3218-3235.

Wright, I. J., Dong, N., Maire, V., Prentice, I. C., Westoby, M., Diaz, S., . \& \& Leishman, M. R. (2017). Global climatic drivers of leaf size.Science, 357, 917-921.

Wuenscher, J. E. (1970). The effect of leaf hairs of Verbascum thapsus on leaf energy exchange. New Phytologist , 69, 65-73.

Table 1 Climates of study sites

\begin{tabular}{|c|c|c|c|c|c|}
\hline Altit & 100 & 700 & 1280 & 1800 & 2400 \\
\hline temperature $\left({ }^{\circ} \mathrm{C}\right){ }^{1}$ & 21.9 & 17.1 & 4 & 12.1 & 8.9 \\
\hline $\left.\mathrm{nm} \mathrm{yr}^{-1}\right)^{1}$ & 3905 & 5934 & 03 & 2277 & 984 \\
\hline$)^{1}$ & 2476 & 1599 & 1550 & 1308 & 1716 \\
\hline & 1.5 & 3.71 & 2.26 & 1.74 & 0.57 \\
\hline & $0 . £$ & 0 . & 0.96 & 1.27 & 2.69 \\
\hline Atmosphere pressure $(\mathrm{kPa})^{2}$ & 100.1 & 93.0 & 87.5 & 81.3 & 75.6 \\
\hline
\end{tabular}

${ }^{1}$ Giambelluca et al. (2014)

2 Calculated by using altitudes and the equation in Campbell \& Norman $(2010)\left[P_{a}=101.3 \exp (-\right.$ altitude/8200)]

Table 2 List of constant parameters and their values

\begin{tabular}{|c|c|c|c|}
\hline Abbreviation & Value & Unit & Meaning \\
\hline$C_{a}$ & 380 & $\mu \mathrm{mol} \mathrm{mol}{ }^{-1}$ & $\mathrm{CO}_{2}$ concentration in the ambient air \\
\hline$c_{p}$ & $29.3^{\mathrm{a}}$ & $\mathrm{J} \mathrm{mol}^{-1} \mathrm{~K}^{-1}$ & Heat capacity of air \\
\hline$D_{H 20}$ & $2.14 \times 10^{-5} \mathrm{a}$ & $\mathrm{m}^{2} \mathrm{~s}^{-1}$ & Diffusion coefficient of heat at $20^{\circ} \mathrm{C}$ \\
\hline$\Delta_{\nu 20}$ & $2.40 \times 10^{-5} \mathrm{a}$ & $\mathrm{m}^{2} \mathrm{~s}^{-1}$ & Diffusion coefficient of water vapor at $20^{\circ} \mathrm{C}$ \\
\hline$D_{c 20}$ & $1.57 \times 10^{-5} \mathrm{a}$ & $\mathrm{m}^{2} \mathrm{~s}^{-1}$ & Diffusion coefficient of $\mathrm{CO}_{2}$ at $20^{\circ} \mathrm{C}$ \\
\hline$D_{0}$ & $1.5^{\mathrm{b}}$ & $\mathrm{kPa}$ & Empirical parameter in the stomatal-conductance model \\
\hline$H_{K c}$ & $79430^{\mathrm{c}}$ & $\mathrm{J} \mathrm{mol}^{-1}$ & Activation energy for $K_{c}$ \\
\hline$H_{K o}$ & $36380^{\mathrm{c}}$ & $\mathrm{J} \mathrm{mol}^{-1}$ & Activation energy for $K_{o}$ \\
\hline$H_{\Gamma^{*}}$ & $37830^{\mathrm{c}}$ & $\mathrm{J} \mathrm{mol}^{-1}$ & Activation energy for $\Gamma^{*}$ \\
\hline$H_{d}$ & $200000^{\mathrm{d}}$ & $\mathrm{J} \mathrm{mol}^{-1}$ & Deactivation energy \\
\hline$K_{c 25}$ & $404.9^{\mathrm{c}}$ & $\mu \mathrm{mol} \mathrm{mol}{ }^{-1}$ & Michaelis-Menten constant of Rubisco activity for $\mathrm{CO}_{2}$ at $25^{\circ} \mathrm{C}$ \\
\hline$K_{o 25}$ & $278.4^{\mathrm{c}}$ & $\mathrm{mmol} \mathrm{mol}{ }^{-1}$ & Michaelis-Menten constant of Rubisco activity for $\mathrm{O}_{2}$ at $25^{\circ} \mathrm{C}$ \\
\hline
\end{tabular}




\begin{tabular}{llll}
\hline Abbreviation & Value & Unit & Meaning \\
\hline$O$ & 210 & $\mathrm{mmol} \mathrm{mol}^{-1}$ & $\mathrm{O}_{2}$ concentration in the ambient air \\
$R$ & $8.314^{\mathrm{a}}$ & $\mathrm{J} \mathrm{mol}^{-1} \mathrm{~K}^{-1}$ & Gas constant \\
$r$ & $0.2^{\mathrm{e}}$ & - & Reflectance of shortwave irradiance (albedo) \\
$a$ & $0.2^{\mathrm{e}}$ & - & Quantum yield \\
$a_{\mathrm{S}}$ & $0.6^{\mathrm{e}}$ & - & Absorptance of shortwave by leaf \\
$a_{\lambda}$ & $0.96^{\mathrm{e}}$ & - & Absorptance of longwave by leaf \\
$\Gamma$ & $42.75^{\mathrm{c}}$ & $\mu \mathrm{mol} \mathrm{mol}^{-1}$ & $\mathrm{CO} 2$ compensation point at $25^{\circ} \mathrm{C}$ \\
$\epsilon$ & $0.97^{\mathrm{e}}$ & - & Emissivity of longwave by leaf \\
$\vartheta$ & $0.95^{\mathrm{e}}$ & - & Curvature of the irradiance response curve \\
$\lambda$ & $44000^{\mathrm{a}}$ & $\mathrm{J} \mathrm{mol}^{-1}$ & Latent heat of vaporization \\
$\sigma$ & $5.6697 \times 10^{-8} \mathrm{a}$ & $\mathrm{W} \mathrm{m}^{-2} \mathrm{~K}^{-4}$ & Stefan-Boltzmann constant \\
\hline
\end{tabular}

${ }^{a}$ Campbell \& Norman (2010)

b Leuning (1995)

${ }^{\mathrm{c}}$ Bernacchi et al. (2001)

${ }^{\mathrm{d}}$ Kattge \& Knorr (2007)

e Jones (2014)

Table 3 Leaf traits. Mean \pm SD.

\begin{tabular}{|c|c|c|c|c|c|}
\hline Altitude (m) & 100 & 700 & 1280 & 1800 & 2400 \\
\hline LaminaLMA $\left(\mathrm{g} \mathrm{m}^{-2}\right)$ & $162.5 \pm 18.5$ & $178.4 \pm 33.1$ & $214.9 \pm 21.7$ & $244.9 \pm 20.3$ & $265.7 \pm 26.5$ \\
\hline TrichomeLMA $\left(\mathrm{g} \mathrm{m}^{-2}\right)$ & $20.8 \pm 15.8$ & $9.3 \pm 18.4$ & $41.9 \pm 17.1$ & $51.9 \pm 28.9$ & $154.3 \pm 23.1$ \\
\hline Lamina thickness (mm) & $0.369 \pm 0.030$ & $403 \pm 0.047$ & $0.481 \pm 0.052$ & $0.516 \pm 0.046$ & $0.595 \pm 0.054$ \\
\hline Trichome thickness (mm) & $0.082 \pm 0.048$ & $050 \pm 0.054$ & $0.172 \pm 0.079$ & $0.226 \pm 0.117$ & $0.559 \pm 0.104$ \\
\hline Leaf area $\left(\mathrm{cm}^{2}\right)$ & $8.84 \pm 2.04$ & $10.35 \pm 1.68$ & $6.32 \pm 1.70$ & $5.40 \pm 0.89$ & $3.33 \pm 0.68$ \\
\hline Characteristic dimension $(\mathrm{cm})^{\mathrm{b}}$ & $2.34 \pm 0.25$ & $2.53 \pm 0.21$ & $2.03 \pm 0.21$ & $1.92 \pm 0.11$ & $1.66 \pm 0.08$ \\
\hline$V_{c \max }\left(\mu \mathrm{mol} \mathrm{m}{ }^{-2} \mathrm{~s}^{-1}\right)^{\mathrm{c}}$ & $86.2 \pm 15.5$ & $65.9 \pm 18.3$ & $38.0 \pm 2.8$ & $37.0 \pm 7.9$ & $32.2 \pm 4.0$ \\
\hline 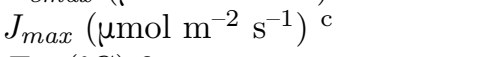 & $97.5 \pm 15.1$ & $109.4 \pm 20.2$ & $87.7 \pm 7.8$ & $94.4 \pm 12.9$ & $102.6 \pm 8.4$ \\
\hline$T_{M}\left({ }^{\circ} \mathrm{C}\right)^{\mathrm{c}}$ & $31.0 \pm 0.9$ & $29.4 \pm 0.7$ & $24.5 \pm 0.7$ & $23.4 \pm 1.0$ & $19.3 \pm 0.7$ \\
\hline$\Delta H_{\sigma_{\mathrm{S}}}\left(\mathrm{J} \mathrm{mol}^{-1}\right)$ & $119033 \pm 20845$ & $119033 \pm 20845$ & $119033 \pm 20845$ & $119033 \pm 20845$ & $119033 \pm 20$ \\
\hline$\Delta \Sigma_{\sigma_{\mathrm{S}}}\left(\mathrm{J} \mathrm{K}^{-1} \mathrm{~mol}^{-1}\right)$ & $664.2 \pm 5.9$ & $664.2 \pm 5.9$ & $664.2 \pm 5.9$ & $664.2 \pm 5.9$ & $664.2 \pm 5.9$ \\
\hline$\Delta H_{\Theta}\left(\mathrm{J} \mathrm{mol}^{-1}\right)$ & $79206 \pm 17520$ & $79206 \pm 17520$ & $79206 \pm 17520$ & $79206 \pm 17520$ & $79206 \pm 175$ \\
\hline$\Delta \Sigma_{\Theta}\left(\mathrm{J} \mathrm{K}^{-1} \mathrm{~mol}^{-1}\right)$ & $667.9 \pm 4.1$ & $667.9 \pm 4.1$ & $667.9 \pm 4.1$ & $667.9 \pm 4.1$ & $667.9 \pm 4.1$ \\
\hline$\Delta H_{P \delta}\left(\mathrm{J} \mathrm{mol}^{-1}\right)$ & $41520 \pm 13896$ & $41520 \pm 13896$ & $41520 \pm 13896$ & $41520 \pm 13896$ & $41520 \pm 138$ \\
\hline$a^{\mathrm{d}}$ & $2.67 \pm 0.43$ & $2.67 \pm 0.43$ & $2.67 \pm 0.43$ & $2.67 \pm 0.43$ & $2.67 \pm 0.43$ \\
\hline$g_{0}$ & $0.03 \pm 0.01$ & $0.03 \pm 0.01$ & $0.03 \pm 0.01$ & $0.03 \pm 0.01$ & $0.03 \pm 0.01$ \\
\hline
\end{tabular}

${ }^{\text {a }}$ Kruskal-Wallis test. ${ }^{* * *}: p<0.001{ }^{* *}: p<0.01{ }^{*}: p<0.05 ;^{+}: p<0.10$, n.s.: $p$ [?] 0.10 .

b Characteristic dimension was calculated as the average length of the major and minor axes (leaf width) multiplied by 0.72 (Campbell \& Norman, 2010).

c $V_{c \max }$ and $J_{\max }$ were measured at different leaf temperature $\left(T_{M}\right)$ for each elevational site. The values of the 100, 1280, and $2400 \mathrm{~m}$ sites partially included the data from Amada et al. (2017).

${ }^{\mathrm{d}}$ In terms of the ecological significance of stomatal coefficient ( $a$ ), leaves with smaller $a$ tend to keep lower $g_{c s}$ irrespective of environmental conditions, i.e., conservative stomatal behavior (isohydric leaves) while leaves 
with larger $a$ can have higher $g_{c s}$ under optimum conditions, i.e., acquisitive stomatal behavior (anisohydric leaves) (see Appendix S3).

\section{Figure legends}

Fig. 1 : A conceptional image for "direct effects" and "indirect effects" of leaf-trichome resistance on gas exchanges. Inb and $\mathbf{c}$, blue and red arrows represent the direct effects (i.e., increasing diffusion resistance for $\mathrm{CO}_{2}$ and $\mathrm{H}_{2} \mathrm{O}$ fluxes) and the indirect effects (i.e., enhancing gas diffusion due to increased leaf temperature via increasing resistance for heat fluxes) of leaf-trichome resistance, respectively. Wide grey arrows on the $y$-axis represent the "combined effects" of leaf-trichomes resistance on the photosynthetic and transpiration rate.

Fig. 2 : Representative diurnal variations in temperature of leaves either trichome-shaved or non- shaved (intact) along with diurnal variations in air temperature and relative humidity at four elevational sites (a , $\mathbf{c}, \mathbf{e}, \mathbf{g})$. Difference in the temperature between intact and trichome-shaved leaves are shown where the positive values indicate higher temperature in the intact leaves $(\mathbf{b}, \mathbf{d}, \mathbf{f}, \mathbf{h})$. These three days included typical sunny days and cloudy or rainy days $(8 / 9 / 2017-8 / 11 / 2017$ in the $2400-\mathrm{m}$ site, $8 / 10 / 2017-8 / 12 / 2017$ in the 1800 -m site, $8 / 13 / 2017-8 / 15 / 2017$ in the $1200-m$ site, and 8/14/2017-8/16/2017 in the $700-m$ site). The error bars represent standard error.

Fig. 3 : Relationship between trichome thickness and the temperature differences between intact and trichome-shaved leaves at the $1800 \mathrm{~m}$ site (air temperature $22.0 \pm 1.0^{\circ} \mathrm{C}$ ). Positive values represent that leaf temperature was higher in leaves with leaf trichomes than in their compared leaves without leaf trichomes. The points and error bars represent mean values and standard errors for three days.

Fig. 4 : Environmental variables, simulated leaf temperature, and gas-exchange characteristics at five elevational sites. Field measured air temperature, relative humidity, and PPFD (photosynthetic photon flux density) for the simulation analyses $(\mathbf{a}, \mathbf{b})$, calculated diurnal variations in leaf temperature, difference in temperature between leaf and air, the photosynthetic rate, and the transpiration rate of leaves with the mean traits values for each site $(\mathbf{c}, \mathbf{d}, \mathbf{e}, \mathbf{f})$, and the effects of leaf-trichome resistance on leaf temperature, the photosynthetic rate, the transpiration rate which were calculated as differences between leaves with and without leaf-trichome resistance $(\mathbf{g}, \mathbf{h}, \mathbf{i})$. Positive values mean that leaves with trichomes have higher values than those without trichomes.

Fig. 5 : The calculated values of the $\mathrm{H}_{2} \mathrm{O}$-flux resistances (a ), the heat-flux resistances (b ), the daily photosynthetic rate $(\mathbf{d})$, the daily transpiration rate (e), and the daily water-use efficiency $(\mathbf{f})$, and the effects of leaf-trichome resistance on each physiological characteristic $(\mathbf{c}, \mathbf{g})$ in the simulation analyses. In $\mathbf{c}$ andg, positive values represent that values are greater in leaves with trichomes than those without trichomes (see Eq. 1).

Fig. 6 : Changes in effects of leaf-trichome resistance on the resistance on the $\mathrm{H}_{2} \mathrm{O}$-flux resistances (a ), the heat-flux resistances (b ), mean and maximum leaf temperature at daytime $(\mathbf{c}, \mathbf{d})$, the daily photosynthetic rate (e), the daily transpiration rate (f), and the daily WUE ( $\mathbf{g}$ ) at each elevational site with varying trichome thickness in the simulation analyses. Positive values represent that values are greater in leaves with trichomes than those without trichomes (see Eq. 1). Circle cross points represent the values when the average trichome thickness for each elevational site was used. The error bar represents the standard deviation of trichome thickness for each elevational site (Table 3).

Fig. 7 : Simulated photosynthetic rates $(A)$ as a function of trichome thickness and characteristic leaf dimension (an indicator of leaf width) for conditions of stomatal coefficient $(a)=2.5$ and relative humidity $(h)=0.8$ in the sensitivity analyses.a : a heatmap of $A$ calculated for air temperature $\left(T_{a}\right)=20 \operatorname{degC}$ and PPFD $(Q)=2400 \mu \mathrm{mol} \mathrm{m}{ }^{-2} \mathrm{~s}^{-1}$, and plotted against trichome thickness ( $x$-axis; 0.00-1.00 mm) and characteristic leaf dimension $(y$-axis; $1.0-5.0 \mathrm{~cm})$. $\mathbf{b}$ : a heatmap represents to what extent the leaf-trichome 
resistance enhances (orange) or suppresses (navy) $A$ in the same condition as a .c : heatmaps of $A$ calculated for various $T_{a}$ and PPFD and each heatmap in $\mathbf{c}$ is drawn for the same axis as in $\mathbf{a} \cdot \mathbf{d}$ : heatmaps of the effects of leaf-trichome resistance on $A$ calculated for various $T_{a}$ and $Q$ and each heatmap in $\mathbf{d}$ is drawn for the same axis as in $\mathbf{b}$. In $\mathbf{c}$ and $\mathbf{d}$, boxed sections represent $\mathbf{a}$ and $\mathbf{b}$, respectively, and two-way arrows represent temperature ranges at each site.

Fig. 8: Simulated photosynthetic rates $(A)$, transpiration rates $(E)$, and water-use efficiency (WUE) with relative humidity $(h)=0.8$ as a function of leaf traits (trichome thickness, characteristic leaf dimension, stomatal coefficient) and environmental conditions (air temperature, light intensity) in the sensitivity analyses. Similar to Figure 7, each heatmap on the left side represents $A, E$, and WUE in relation to various trichome thickness (x-axis) and characteristic leaf dimension (y-axis), and each heatmap on the right side represents to what extent the leaf-trichome resistance enhances (orange) or suppresses (navy) $A, E$, and WUE in the same set of $\mathrm{x}$ - and $\mathrm{y}$-axis. These simulations are done for different stomatal coefficient $(a)$. The simulation for different relative humidity $(h)$ was shown in Figure S9 $(h=0.2)$ and S10 $(a=0.5)$.

(a)

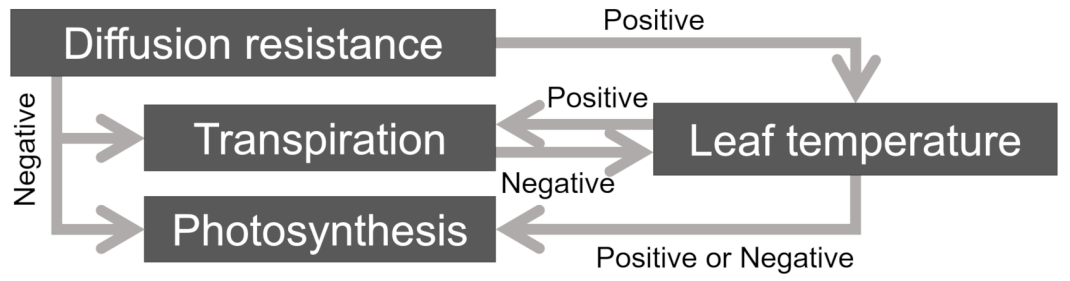

(b)

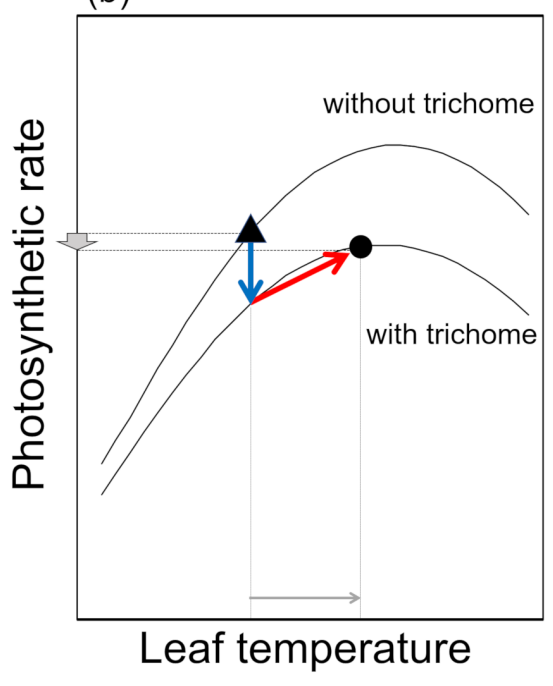

(c)

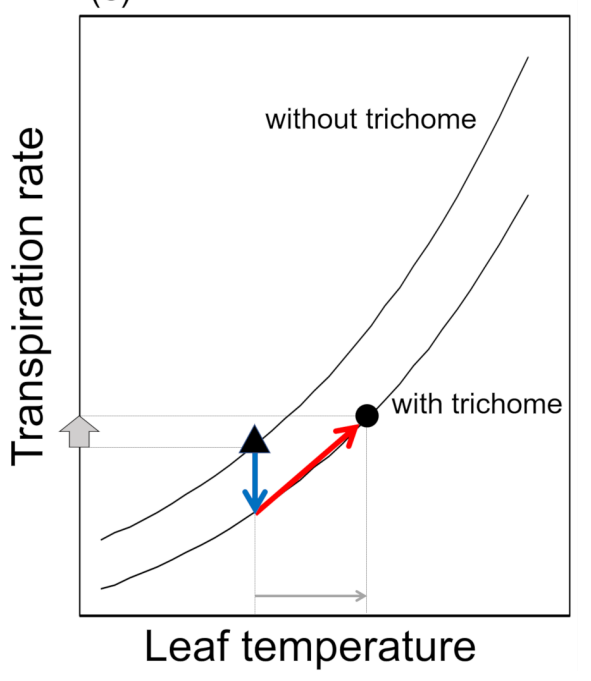




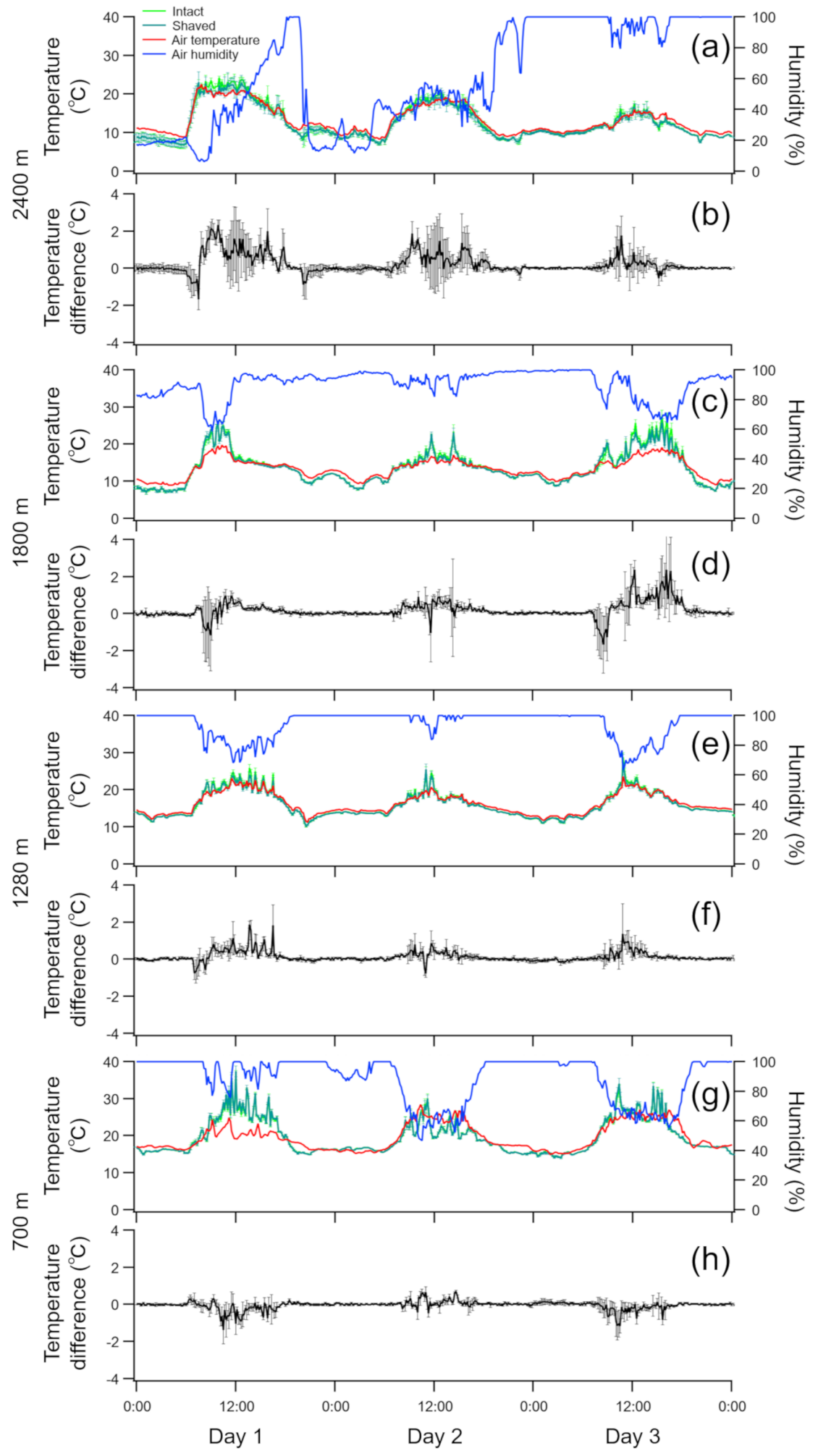




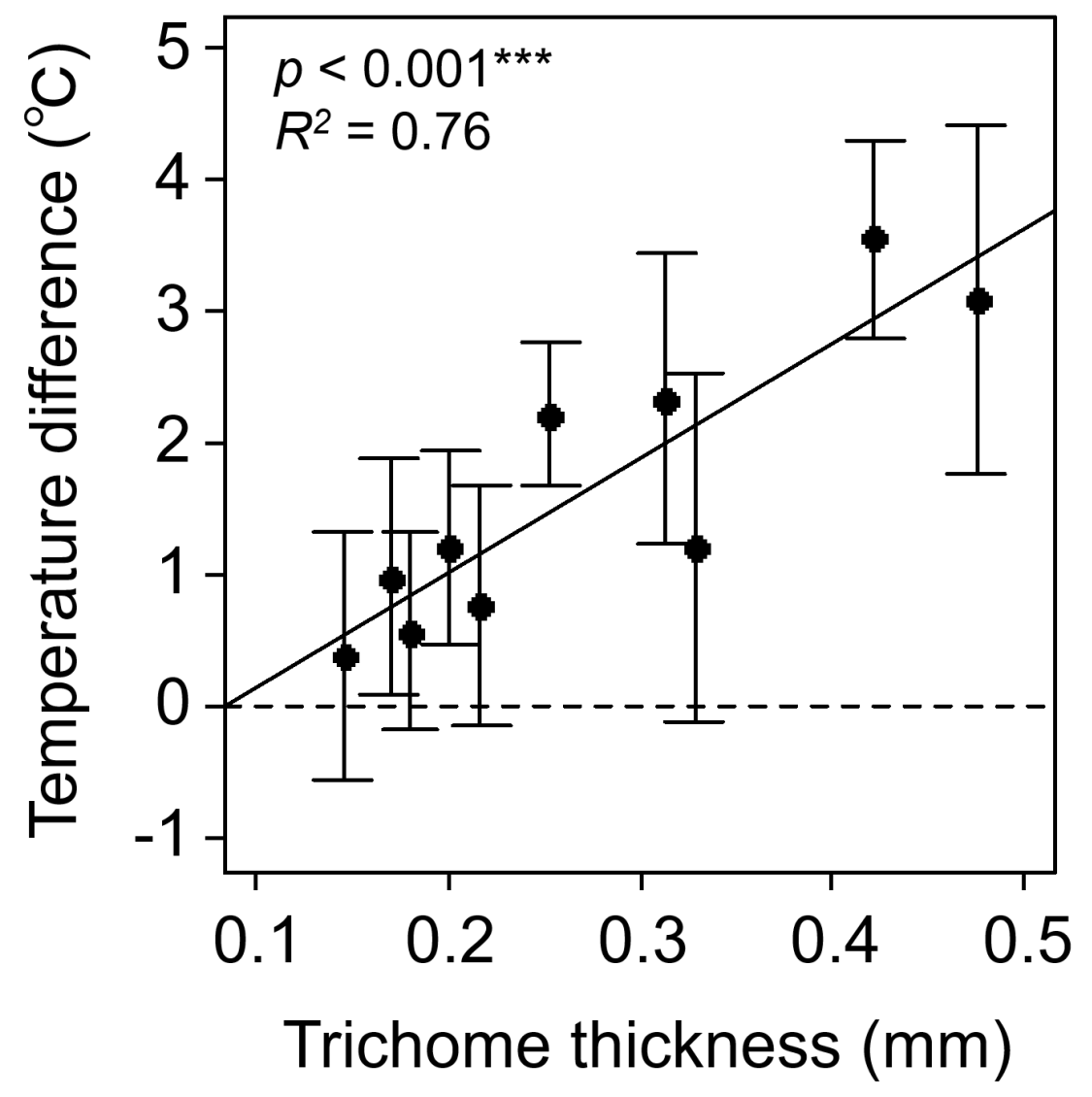




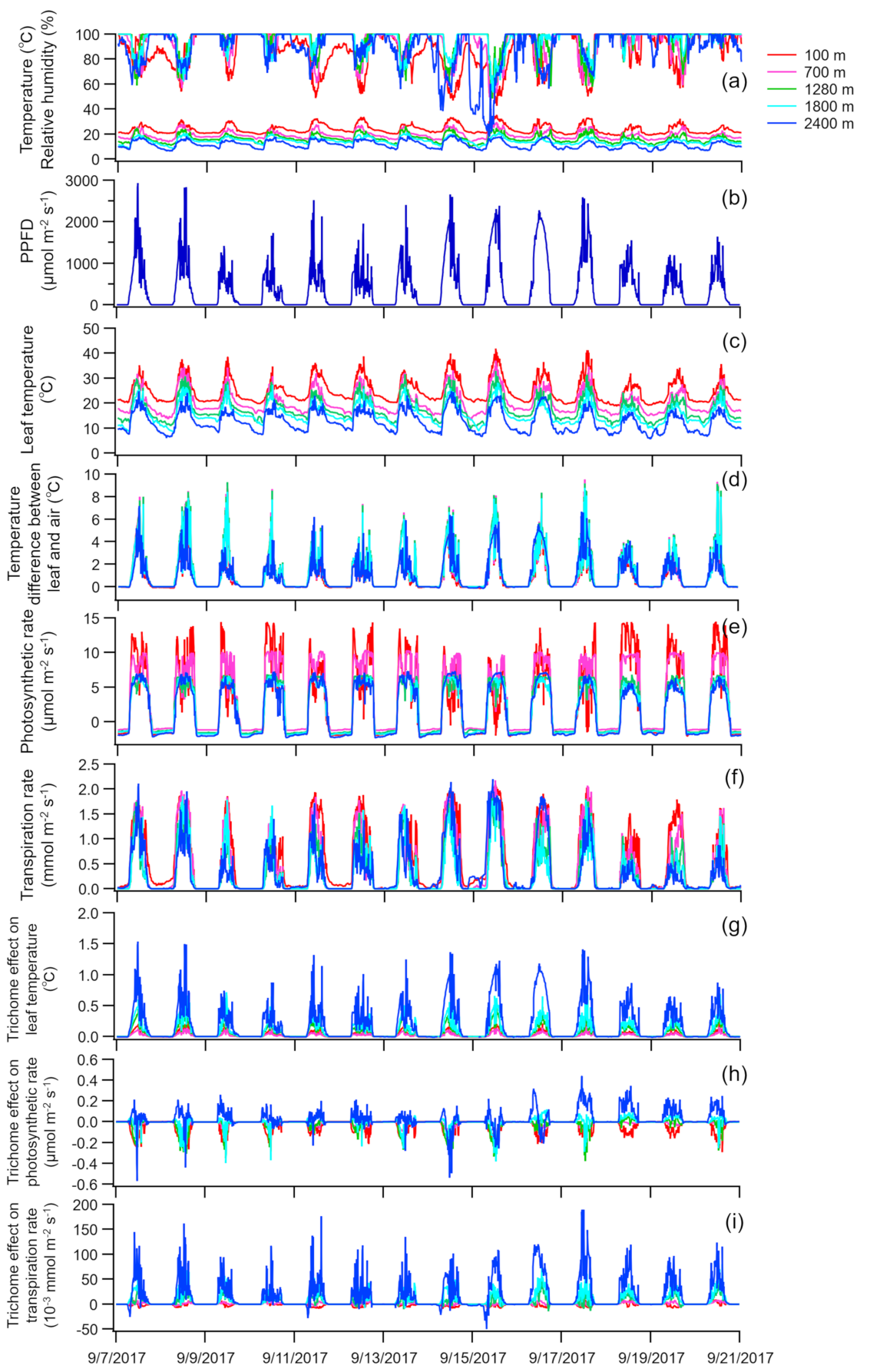



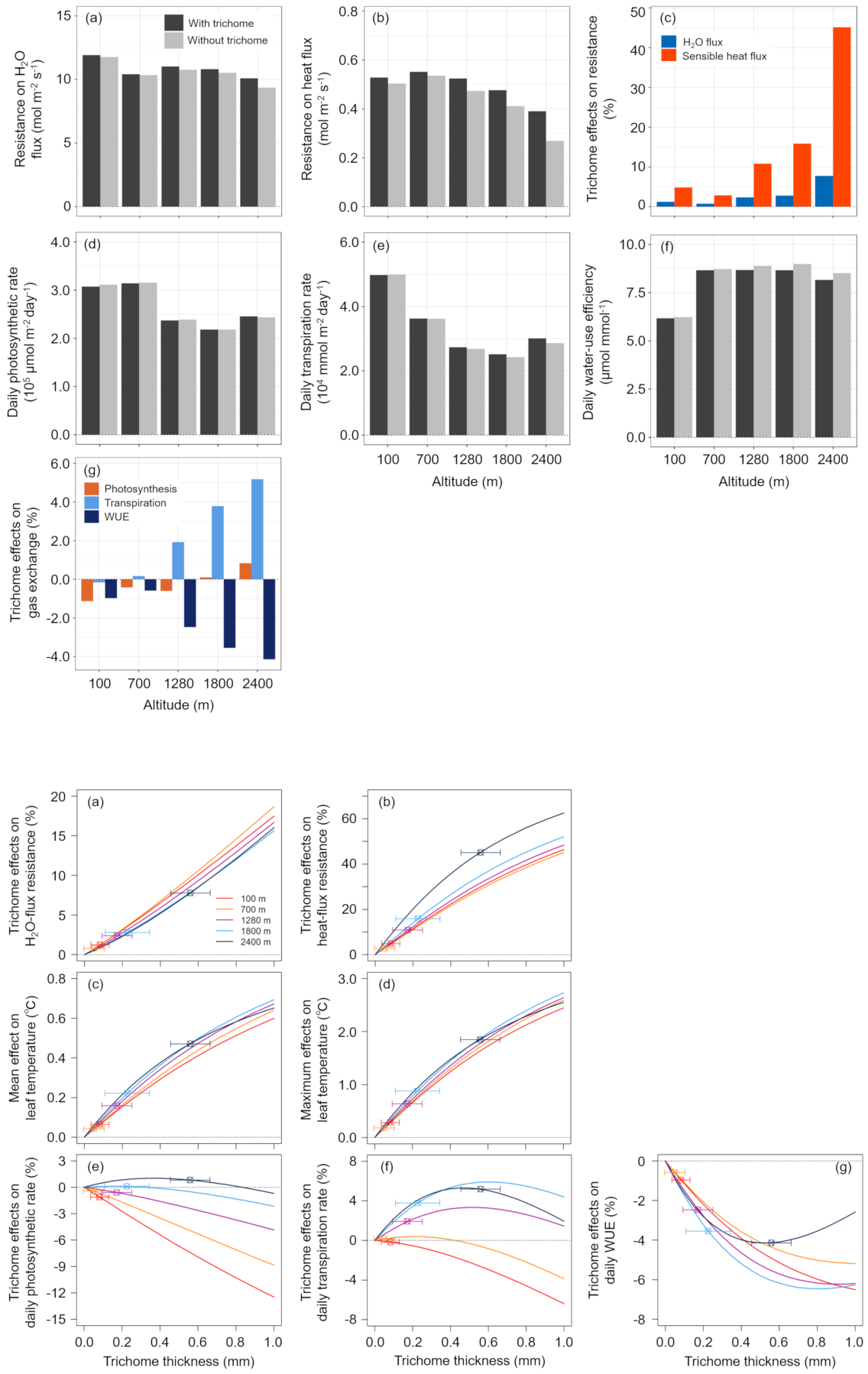

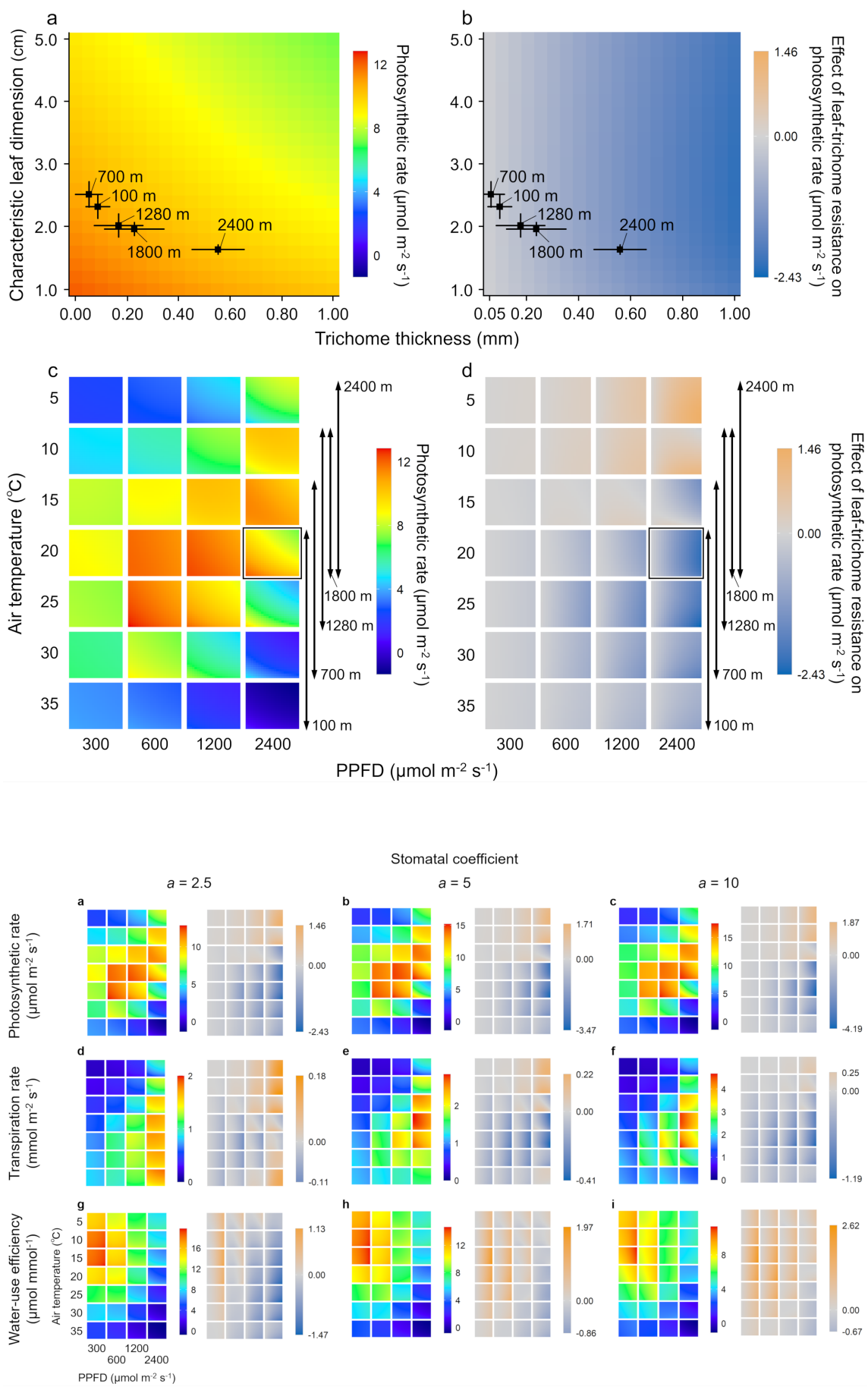